\title{
Disaster Prevention through a harmonized Framework for High Reliability Organisations
}

\author{
Agwu Emele Agwu* ${ }^{\text {** }}$, Ashraf Labib ${ }^{\mathrm{a}}$, Sara Hadleigh-Dunn ${ }^{\mathbf{b}}$, \\ *Corresponding author: agwu.agwu@myport.ac.uk, Tel: +1-780-205-2376 \\ a Department of Operations and Systems Management, Faculty of Business and Law, University of Portsmouth, \\ Portland Building, P01 3DE, United Kingdom \\ ${ }^{\mathrm{b}}$ Strategy Enterprise and Innovation, Faculty of Business and Law, University of Portsmouth, Richmond \\ Building, P01 3DE, United Kingdom
}

\begin{abstract}
The increasing havoc wrecked by catastrophic incidents on organisations worldwide, as well as the increasing devastating effects of these incidents, has necessitated the development of a framework to improve the reliability of organisations. Despite operating in tightly coupled and complex technologies, high reliability organisations (HROs) continue to operate mindfully with minimal incidents. Given that most disasters have occurred in organisations and industries not considered as truly HROs, this paper argues that applying organisational learning from HROs across diverse organisations in different industries could potentially reduce organisational disasters. This paper recognised the numerous researches in HRO theory, but noticed the unavailability of a harmonized measurable framework that could be standardized and applied across diverse organisations. Using the HRO principles, this paper conducted a research in 8 organisations, in 3 industries across 2 continents. It developed the organisational reliability maturity model $\left(\mathrm{ORM}^{2}\right)$ to track the progression organisations through 5 maturity levels. It developed the framework for organisational reliability maturity (FORM) to measure maturity levels of organisations, predict potentials for disasters, benchmark, and improvement organisations. It is hoped that this paper will deepen existing research in disaster prevention and HRO theory, while opening up new areas of knowledge.
\end{abstract}

Keywords: Disasters, Organisational Learning, High Reliability Organisations, Maturity, Benchmarking, Organisational Improvement, Framework 


\section{Introduction}

The old English saying “don't spoil the ship for a ha'p'orth of tar”, which means that one should not risk the failure of a large project by trying to make savings on trivial things, suggests that catastrophic failures could be prevented by implementing minor but timely activities. Studies have shown that most catastrophic failures have been caused by series of seemingly minor and retrospectively avoidable individual and organisational behaviours (Labib \& Read, 2013; 2015; Labib, 2014; Savioja et al, 2014; Waring, 2015; Harvey et al, 2016; Li, 2016). Despite operating with complex technologies in highly hazardous environments, and with tightly coupled processes, where minor failures could result in catastrophes, certain organisations continue to operate with nearly error free and harm free performance. They continuously avoid failures, or operate such that failures do not result in catastrophe. Should catastrophic failures eventually occur, these organisations are able to withstand the consequences. Weick \& Sutcliffe, $(2007 ; 2015)$ referred to them as High Reliability Organisations (HROs). Given the continuously remarkable safety records, these highly reliable organisations are therefore highly safer organisations.

Research into organisational reliability has been conducted in a number of industries. These have included transportation, aviation and military (Roberts et al, 1994; La Porte \& Consolini, 1998; Busby, 2006; Jeffcott et al, 2006; O’Neil, 2011); nuclear (Bierly \& Spender, 1995; Ashley et al, 2009); fire and disasters (Keller, 2004; Weick \& Sutcliffe, 2007; Berardi, 2010); and healthcare (Baker et al, 2006; Frankel et al 2006; Madsen et al, 2006; Roberts et al 2005; Stralen et al 2006; Tamuz \& Harrison, 2006; Vogus \& Sutcliffe, 2007a; Costella et al, 2009; Riley, 2009; Samuels, 2010; Sutcliffe, 2011; Hales \& Chakravorty, 2016). There have also been some HRO research with respect to space (Schulman, 2008); energy (Hoffmann et al, 1995; Miller, 2009; Hopkins, 2009; Lekka \& Sugden, 2011); education (Stringfield, 1995; Taylor \& Angelle, 2000; Azzaro, 2005; Bellamy et al, 2005; Stringfield et al, 2008); food retail (Ciravenga \& Brenes, 2016); Information technology ( Valorinta, 2009; Carlo et al, 2012) and virtual organisations (Grabowski \& Roberts, 2016). Some have aimed at the relationship with other concepts such as resilience engineering (Aven \& Krohn, 2014; Righi et al, 2015; Bergstrom et al, 2015; Haavik et al, 2016; Harvey et al, 2016; Le Coze, 2016) and safety (Vogus \& Sutcliffe, 2007a; Vogus \& Sutcliffe, 2007b; Ausserhofer et al, 2013; Vogus et al, 2014; Vogus \& Iacobucci, 2016). There is no evidence of a research conducted across different types of organisations at the same time to test the theory, demonstrate how it could be progressively achieved. Such research would not only provide a balanced perspective about the HRO theory, but would also show the extent to which the theory could be standardized 
across organisations with diverse characteristics. Furthermore, HRO researches have been mostly reactive. While some have studied how the HRO theory could have helped avoid catastrophic events retrospectively, others have mostly studied the HROs with the view to understanding behaviours make them reliable - the end point. This research is more interested in the "journey" than the "end point" - it is more interested in how organisations could become reliable.

This paper expands the HRO study to different and diverse organisations at the same time horizon using the same methodology in an attempt to obtain a balanced data. It tries to demonstrate that organisations could make progressive improvements over time as they tend towards higher reliability. To achieve this, there must be a means to measure the expected behaviours from HROs, assess the extent to which organisations exhibit these behaviours, as well as a framework that guides the organisation towards becoming HROs. Zietsma et al (2002) had identified the four feed-forward learning process as means for organisations to learn in the face of considerable external changes. Tsoukas \& Mylonopoulos (2004) focused on the processes, practices and strategies through which knowledge is constructed and created in organisations. While these are important aspects towards achieving reliability, they do not specify simplified step wise approaches for adoption. Weick et al (2008) acknowledges the need for a roadmap for HRO implementation. Hales \& Chakravorty (2015) attempted to "articulate" these and "show how to systematically implement HROs using a soft research methods approach moderated with mindfulness". This purely qualitative work involved a close collaboration between the researchers and the different people within a hospital on issues of organisational reliability, as well as training and mentoring. It does not however answer some basic question: How do we measure the reliability of the organisation? At what point does the organisation move from being reliable to not being reliable or vice versa? How do we compare the reliability of different organisations? How do we measure which organisation to apply these systematic processes to? These could be achieved through a staged maturity framework.

Chassin \& Loeb $(2011 ; 2013)$ had developed a staged maturity model to guide organisations towards the path of higher reliability (Sullivan et al, 2016). This had focused on the organisational characteristics of leadership, safety culture and process improvement, mapped in three maturity stages of minimal, developing and approaching reliability. They rightly recommended organisational self-assessment as an important first step. While this is very detailed within the context it addresses, the model focuses narrowly on a healthcare organisation with no clear path to expand to different industries. Furthermore, they focused narrowly on the 
three dimensions of leadership, safety culture and process improvement. While these are worthy characteristics, organisational mindfulness goes beyond leadership and safety culture. It is concerned with a focus on a "clear and detailed comprehension of emerging threats, and on factors that interfere with such comprehension' (Weick \& Sutcliffe, 2007). It is organisational consciousness characterized by 'being (1) situated in the present, (2) sensitive to context and perspectives, (3) guided (but not governed) by rules and routines' (Langer, 2014). Mindfulness ensures everyone, not just leadership, works and communicates collectively with a common purpose to focus on what really matters based on current situational realities (Sutcliffe et al, 2016; Agwu, 2018). Organisational mindfulness comprises of five interrelated behaviours at multiple organisational levels: preoccupation with failure, reluctance to simplify, sensitivity to operations, commitment to resilience, and deference to expertise (Weick \& Sutcliffe, 2015). Developing the model in line with these five interrelated behaviours at multiple organisational levels would therefore make more sense. It would enhance the identification of expected behaviours at different maturity levels for each of the five mindfulness principles, making it easy to actualize the organisational self-assessment goal identified by Chassin \& Loeb $(2011 ; 2013)$, and develop improvement plan.

The paper therefore developed the Organisational Reliability Maturity Model $\left(\mathrm{ORM}^{2}\right)$ as a five stage maturity model that maps organisations into various stages of organisational reliability. It further developed the Framework for Organisational Reliability Maturity (FORM), a framework that leverages on the Organisational Reliability Maturity Model $\left(\mathrm{ORM}^{2}\right)$ to develop a stepwise organisational reliability learning and improvement process. The research behind this paper was conducted in eight organisations purposively selected from three industries between July 2016 and January 2017, using the same research methods. The next section will further discuss some related concepts such as disasters, HROs and organisational learning. Section three will describe the data collection and analysis process, and the results. Section four will describe the proposed maturity model and measurement framework for organisational reliability maturity, while section five will describe the various applications of the measurement framework. Section six shall conclude paper. 


\section{Disasters, HROs and Organisational Learning}

2.1 Disasters

Labib \& Read (2015) considered disasters as black swans with the distinct attributes of rarity, extreme impact, and retrospective predictability. Within the late twentieth and the twenty first centuries, the incidence of disasters has accelerated. This is due in part to the increasing complexity of the world and its technologies (Taleb, 2010), increasing populations and environmental changes (Rougier et al, 2010), and increasing stakeholder demands. A trend of these safety incidents over the years ties the causative factors to mostly organisational and individual errors. Reviews of the 1912 Titanic disaster that killed an estimated 1514 passengers and crew, considered management decisions and other human factors as key causative factors (Labib \& Read, 2013). The March 2005 BP Texas city disaster led to 15 fatalities, injured 170 people, and resulted in damages worth hundreds of millions of dollars (Labib \& Read, 2013). Again, management decisions and employees' actions and inactions were considered to be the major causative factors. Similarly, management decisions were among the contributory factors to the April 1986 Chernobyl nuclear disaster in Ukraine (INSAG, 1992), NASA's Columbia's incident of 2003 (Labib \& Read, 2013); the 2010 BP Deep water horizon incident; (Labib, 2014); the Rio-Paris Flight 447 (Moura et al, 2016), the 2011 Fukushima nuclear disaster (Labib \& Harris, 2015), and the 2000 Concorde crash (Labib, 2014) all share similar characteristics of the significance of management and people related retrospectively avoidable causative factors. In some cases, the organisations involved could not recover from the social and financial impact of these disasters. In some other cases, the organisations were resilient and withstood the financial and social impact and evolved to become stronger and more competitive organisations. This paper hopes to tap from the understanding of the differences between these organisations to develop a harmonized framework for organisational reliability.

A lot of organisations and industries could certainly benefit from HRO theory implementation. Hudson (2007) described the need to oil and gas organisations highly reliable. This is more imperative given the frequency and severity of incidents within the industry over the last few decades. Although the work by Hudson (2007) stayed more within the ambits of safety, it however set the stage for a more robust HRO implementation for oil and gas organisations. The work developed a staged maturity model that tracks the safety culture of organisations through five maturity levels: 'pathological', reactive, 'calculative', 'proactive', and 'generative'. Alothman (2016) used two analytical paradigms - the quantitative scales audit and the qualitative template analysis to assess the organisational reliability of an oil and gas organisation. 
The manufacturing cluster is often overlooked by the HRO researchers despite the potential for disasters. Since the Lawrence Massachusetts Pemberton Mill disaster in January 101960 that resulted in 145 fatalities and 166 serious injuries, the manufacturing industry has continued to witness catastrophic incidents. Between September 2012 and April 2013 (table 1), recorded industrial disasters contributed to over 1530 mostly retrospectively avoidable loss of lives, potentially preventable through mindfulness.

Table 1: List of Industrial Disasters

\begin{tabular}{|l|l|l|l|}
\hline Date & Incident & Location & Effect \\
\hline January 10. 1860 & Pemberton Mill Factory Collapse & $\begin{array}{l}\text { Lawrence, } \\
\text { Massachusetts, USA }\end{array}$ & 154 Fatalities, 166 injuries \\
\hline March 20.1905 & Shoe factory explosion & $\begin{array}{l}\text { Brockton, Massachusetts, } \\
\text { USA }\end{array}$ & 58 Fatalities, 150 Injuries \\
\hline March 25.1911 & Triangle Shirtwaist Factory fire & New York City, USA & Over 100 Fatalities \\
\hline Nov 23.1984 & MESIT Factory Collapse & Czechoslovakia & 18 Fatalities, 43 Injuries \\
\hline May 4. 1988 & PEPCON Chemical Explosion & Nevada, USA & 2 Fatalities, Over 300 Injuries \\
\hline May 10.1992 & Kader Toy Factory Fire & Thailand & 188 Fatalities, Multiple Injuries \\
\hline May 13.2000 & Enscede Fireworks Depot Disaster & Enscede, The Netherlands & $\begin{array}{l}\text { 24 Fatalities, 947 injuries, 1500 } \\
\text { homes destroyed, Over US\$300 } \\
\text { million insured los ses }\end{array}$ \\
\hline Nov 3.2004 & Seest Fireworks factory Disaster & Kolding, Denmark & $\begin{array}{l}\text { 1 fatality, 24 Injuries, 2107 } \\
\text { buildings destroyed, about 100 } \\
\text { million Euros insured damage }\end{array}$ \\
\hline Dec 6. 2006 & Falk Gear Factory Explosion & Milwaukee, Wisconsin & $\begin{array}{l}\text { 3 fatalities, 47 Injuries, Multiple } \\
\text { building damages. }\end{array}$ \\
\hline April 18.2007 & Qinghe Steel Factory Disaster & China & 32 Fatalities, multiplr injuries \\
\hline Feb 1.2008 & Fireworks Fire Disaster & Istanbul, Turkey & 22 Fatalities, over 100 Injuries \\
\hline Sept 11.2012 & Ali Garments Factory Explosion & Karachi, Pakistan & 289 Fatalities, Multiple Injuries \\
\hline Nov 24.2012 & Tasreen Factory Disaster & Dhaka, Bangladesh & 112 Fatalities, Multiple Injuries \\
\hline April 24.2013 & Savar Factory Disaster & Dhaka, Bangladesh & 1,129 Fatalities, Multiple Injuries \\
\hline
\end{tabular}

In most of these disasters the "ha'p'orth of tar" was neglected, and in other cases, the acceptable behaviours changed and perceptions of 'norm' shifted. Food contamination could also be another major source of disasters and history is rife with such incidents with multiple fatalities. 732 people were infected with E.coli in 1993 when Jack in the Box restaurant served infected burger across 73 locations in the United States (Schlosser, 2001; Nestle, 2010). 4 children died, and 178 people were left with permanent damage. E.coli outbreak has affected so many other major restaurant chains including KFC, McDonald's, Sizzler, Wendy's, and Taco Bell all with catastrophic consequences. Burger King was forced to recall 25 million pounds of beef from 650 locations in 1997 after E. coli contamination got 16 customers sick (Janofsky, 1997). In 2003, 640 people were affected and 4 died in Pennsylvania, USA, when tainted tomatoes at Chi-Chi's restaurant caused a hepatitis A outbreak. The reputation of the organisation never recovered. The reputation of Chipotle took a major hit in 
2015, when an affected almost 500 customers across 14 states of America (Carr, 2016). 43 restaurants were closed, the stock shrunk by $30 \%$, and nearly one-third of the sales disappeared. This paper posits that these disasters could have been avoided had these organisations taken steps towards improving their mindfulness by adopting the principles of high reliability organisations.

\subsection{High Reliability Organisation (HRO) Theory}

Perrow (1984), had described the inevitability of accidents in complex organisations with the argument that no matter how well a system is managed, accidents are inevitable, as long as the system is characterised by complexity and tight coupling. The HRO researchers countered this with the argument that some organizations, despite complex technologies and tightly coupled processes, have consistently prevented and contained catastrophic failures (Roberts, 1990; LaPorte \& Consolini, 1998) by creating and reinforcing certain behaviours (Weick \& Roberts, 1993). Since the first research in the 1980s, different researchers have studied HROs from different theoretical lenses. Despite their diverse views, their point of commonality considers HROs as nearly error free and harms free organizations (Vogus \& Welbourne, 2003). Weick \& Sutcliffe (2001; 2007; 2015) developed five behaviours that enhance the reliability of an organisation. The first three deal with the capacity of the organisations to anticipate unexpected problems. These are preoccupation with failure, reluctance to simplify, and sensitivity to operations.

Preoccupation with failure is a characteristic of HROs that enables them to actively seek for signals within their systems that could indicate a potential for failure. They continuously learn and improve and consider near misses as progressive cautions that drive proactive and pre-emptive analyses of possible vulnerabilities (Sutcliffe, 2011). They avoid being reactive with failures, rather continuously focus on potential points of failure through management and organisational cultural progressions (Hales \& Chakravorty, 2016). Key preoccupation behaviours of observing, reporting and documenting near misses and incidents are key steps to eliminate or reduce the incubation period in Turner's man-made disaster model (Turner, 1978). The lookouts in Titanic had noticed some haze within the horizon ahead of them but failed to report (Barratt, 2010), thus lack of preoccupation ended up being one of the reasons for the Titanic disaster.

Reluctance to simplify shows how organisations continuously balance simplification and standardization of processes, with undue generalisations. They have standardized processes, yet actively seek divergent viewpoints 
that question received wisdom, uncover blind spots and detect changing demands (Sutcliffe, 2011). The NASA Challenger disaster could have been prevented had the management not oversimplified the flaw in the O-Rings designs when their engineers reported the issue. They had known for over 11 years prior to the crash that the design of the O-rings in the solid rocket booster had a potentially catastrophic flaw, yet they disregarded several warnings from their engineers about the potential catastrophic implication of launching the rocket at low temperatures (Vaughan 1997). They waived 6 launch constraints related to O-rings that could have prevented the launch, and by extension, the disaster. They oversimplified the problem and wrongly defined it as an acceptable risk. With time, these became norms - norm that would lead to catastrophe. Vaughan (1997) called this a "normalization of deviance", a situation where "people within the organization become so much accustomed to a deviant behaviour that they don't consider it as deviant, despite the fact that they far exceed their own rules for the elementary safety". The Challenger example is closely related to preoccupation with failure. NASA received warnings about the potential for disaster, with similar occurrences in the past. The organisation did not consider these near misses as progressive cautions to drive proactive and pre-emptive analyses of possible vulnerabilities (Sutcliffe, 2011).

Finally, sensitivity to operations is the HRO characteristics that determine their responsiveness to the details of their operations, with the right staffing, competence levels, and motivation. They recognize that a solution to one problem may create another problem; they therefore maintain a big picture of their processes and mix their awareness and alertness of expectations with actions that unfold in real time (Weick \& Sutcliffe, 2015). Investigations into the Piper Alpha disaster (Broadribb, 2014), BP Texas City incident (Labib \& Read, 2013) and the Deep Water Horizon incident (Labib, 2014) revealed that the disasters resulted from behaviours related to sensitivity to operations. These include inadequate communication among staff, inadequate communication between staff and management, insufficient duty of care, poor operational decision making by those responsible, breakdown of the chain of command, and inadequate maintenance and safety practices. Others include deviation from procedures, inadequate supervision, unclear chain of command, ambiguity in roles and responsibilities, inadequate hazard identification, inadequate trainings, and delays in reacting to signals.

The last two are principles are concerned with the capacity of the organisations to contain the unanticipated problems when they occur. These are commitment to resilience, and deference to expertise.

Commitment to Resilience is concerned with the ability of organisations to not only effectively anticipate errors 
but also to cope with and bounce back from errors and 'unexpected events' (Weick and Sutcliffe, 2015; Lekka, 2011). The Columbia shuttle had no emergency response processes built into the system to enable effective rescue missions and on-orbit repairs by the shuttle astronauts should the need arise. The emergency response practices leading up to the Texas City and Deepwater Horizon incidents were considered inadequate and at best chaotic by the post disaster investigations.

Deference to Expertise on the other hand shows that HROs rely on a hierarchical structure with clearly defined roles and responsibilities during normal operations. During emergencies however, decision making is yielded to people with the most subject matter knowledge and experience, irrespective of their rank (Weick \& Sutcliffe, 2015). The Piper Alpha incident (Broadribb, 2014), is a clear example of the dangers of not deferring to expertise during emergencies. The staff at the neighbouring platforms Tartan and Claymore were experienced enough to know they should shut down their facilities to reduce the effect of the incident, but waited for shutdown instructions from their hierarchical leadership. The longer they waited for their hierarchical superiors, the more oil was pumped into already flaming Piper Alpha the higher the disaster escalation. Organisations must therefore learn from HROs.

\subsection{Organisational Learning}

Organisational learning is a critical component for organisations to develop competitive advantage (Un \& Cuervo-Cazurra, 2004; Tsoukas \& Mylonopoulus, 2004). For organisational learning to be effective, there must be a flow of knowledge, as well as a reinforcement or change in behaviours (Saka-Helmhout, 2007). Zietsma et al (2002) acknowledged that organisational learning could be achieved through well-defined processes. Tsoukas \& Mylonopoulus (2004) agreed with the well-defined process approach and argued that such knowledge presupposes work and that for the knowledge to be effective there must be clear cut strategies and incentives to shape it. This paper develops the views of Zietsma et al (2002) and Tsoukas \& Mylonopoulus (2004) further by developing the maturity model and maturity framework that outlines well defined processes and clear cut strategies to advance organisational learning. Given the benefits of adopting HROs, it is clear that nontraditional HROs should begin to learn from the HROs. Weick (2002) considered organisational learning from the mindfulness perspective and outlined mindful behaviours that HROs work to improve on, and which organisations must learn from as they tend towards organisational maturity. Provera et al (2010) enhanced this further with emphasis on the "no blame approach to organisation learning" as exhibited by HROs. This paper agrees with both the perspectives Weick (2002) and Provera et al (2010), but argues that learning from HROs 
should be more holistic than narrow and should be backed by empirical data. This paper therefore embarked on research across different organisations in diverse industries in search of empirical data to back up these arguments and in the process developed the framework to measure the mindfulness of organisations with the measurement focusing on specifying the degree of maturity with each dimension (construct) of HRO mindfulness.

\subsection{Maturity Models}

Maturity models are frameworks that describe the methodical progression through successive stages of maturity with incremental maturity behavior towards the desired maturity behaviour. Despite some criticism of maturity models especially in small and medium scale organizations (Beadell, 2009; Huang \& Zhang, 2010; Uskarci \& Demirors, 2017), research indicates that organisations with higher maturity levels are expected to have competitive advantages in the marketplace (Backlund et al, 2014; Nikkhou et al, 2016), and as such would provide opportunities for continuous organisational learning. Uskarci \& Demirors (2017) noted that most of these short comings would largely be the result of the quality and motivation levels of employees during implementation. It would therefore be imperative to emphasize that positive contributions of employees during implementation is key to the success of the maturity model for any size of organisation. Crosby's (1979) quality management maturity model paved the way for research into maturity models. It mapped organisations into five maturity levels: Uncertainty, Awakening, Enlightenment, Wisdom, and Certainty. It worked on the premise that organisations could progress through the five levels and strive towards "perfection" at level "certainty". Recent similar maturity models include maintenance management maturity model (Antil, 1991; Fernandez et al, 2003; Oliveira, 2012), the energy management maturity model (Introna et al, 2014), the portfolio management maturity model (Nikkhou et al, 2016), and the maturity model for production management (Kosieradzka, 2017).

Whereas Crosby's model stems from quality, ORM² stems from reliability. Labib et al (2009) had discussed the many similarities between quality and reliability. They defined reliability as the 'ability of an item to perform a required function under given conditions for a given time interval', and quality as the 'ability of an item to perform a required function under given conditions'. In other words, quality is fitness for purpose at an instant of time, whereas reliability is also fitness for purpose but over a period of time'. Given these similarities, the maturity model that originated from the quality domain could help organisations achieve higher reliability. As most disasters have occurred in organizations outside the traditional HROs, while HROs have sustained relative 
stability in reliability and safety, this paper expects the HRO behaviours to be the benchmark behaviours for maturity level five.

\subsection{Methodology}

\subsection{Data Collection}

The research was conducted using a quota based purposive sampling technique to determine organisations where rich and contrasting information would be obtained. The three industries: oil and gas, beverage manufacturing, and restaurant chains, were selected to highlight industries often ignored by HRO researchers, but with potentials for incidents of catastrophic proportions. The organisations were purposively selected with considerations to contrasting sizes, geographical spread, age, and market share, to reduce potential bias and add depth and diversity to the data. Organisation A was purposively selected due to perceived expectations that it should mirror the expected behaviours from an HRO. This is purely for triangulation purposes and to help identify and establish benchmark behaviours for organisational reliability. Organisations B, C, D are peers within the oil and gas industry with contrasting sizes, geographical spread and years in operation. Organisations $\mathrm{E}$ and $\mathrm{F}$; and $\mathrm{G}$ and $\mathrm{G}$ are also peers with contrasting characteristics. Table 2 describes the organisations. The organisations are not necessarily the same level of risk takers but the expectation is that in this diversity, the different behaviours of diverse organisations at different maturity levels could help deepen the research.

Table 2: Summary of organisations

\begin{tabular}{|c|c|c|c|}
\hline \multicolumn{4}{|c|}{ RESEARCH PARTICIPAPTION } \\
\hline Organisation & Considerations & Questionnaires & Interviews \\
\hline \multicolumn{4}{|c|}{ Oil and Gas } \\
\hline A & $\begin{array}{l}\text { Multinational organization. Expected enhanced processes and } \\
\text { culture. To be used for triangulation }\end{array}$ & 40 & 6 \\
\hline B & $\begin{array}{l}\text { Multinational organization. Expected enhanced processes and } \\
\text { culture. Large employee base. }\end{array}$ & 50 & 10 \\
\hline C & $\begin{array}{l}\text { cal organization. Smaller than B, but Larger than D. Newer than } \\
\text { B, but older than D. }\end{array}$ & 30 & 5 \\
\hline D & Local organization. New. Small employee base & 30 & 5 \\
\hline \multicolumn{4}{|c|}{ Beverage Manufacturing } \\
\hline $\mathbf{E}$ & Large operational base. National spread. Decades of operation. & 50 & 10 \\
\hline $\mathbf{F}$ & Regional operational base. New organization & 50 & 10 \\
\hline \multicolumn{4}{|c|}{ Restaurant Chain } \\
\hline G & Regional operational base. New organization & 50 & 10 \\
\hline H & Large operations base. National spread. Decades of operation. & 70 & 15 \\
\hline
\end{tabular}

The sample was demographically stratified in terms of current responsibility and years of experience. Considering current responsibility, the research adopted a medium span of control (Gupta, 2010) of 10-20\% $20-40 \%-40-60 \%$ ratio for managers, supervisors, and staff. Span of control here refers to the number of direct reports a particular manager or supervisor has at any given time. The research used a five level experience 
stratification of below three years; between three to seven years; above seven years and below 15 years; 15 to 25 years; and above 25 years to enhance diversity of responses.

The research adopted a pragmatic philosophy. It combined surveys and interviews to obtain objective, verifiable and generalizable data, as well as capture the subjective realities inferred through feelings, intuitions, experiences and individual world views of the diverse respondents. Input to the questionnaires came from Weick \& Sutcliffe $(2007 ; 2015)$ and input from industry experts and refined after the pilot survey. The survey differs from Weick \& Sutcliffe $(2007 ; 2015)$ by increasing the range of questions to include the contributions by industry experts and introducing check questions to enhance the research reliability. In addition, the research introduced a five points rating scale in place of the combination of two point and three points scales used by Weick \& Sutcliffe (2007). Finally the questions followed a logical sequence of events as they would occur in real life, while the respondent is made to become part of the research by the consistent use of the pronouns 'we' and 'our'. The questionnaire has five sections with each section representing one of the five HRO principles. For all questions, the responses ranges from one to five with one representing strongly disagree and five representing strongly disagree. The organisational reliability behaviours are expected to improve as the response tends towards five from one.

The interviews were semi-structured with questions based on the questionnaires but geared towards obtaining the personal impressions of the interviewee. These were used to triangulate and validate the results. The selection of interviewees followed the same methods as the questionnaires and stratified to accommodate diversity in terms of experience and responsibility. The questions were designed to get the interviewee talking with "what", and "how" questions and follow up questions. For example: "If someone interrupts the process to forestall a catastrophic failure, what would happen? What if it turns out to be a false alarm?"

\subsection{The Results}

In terms of responsibilities, the result validated the expected span of control with an average ratio of $15 \%-37 \%$ - $48 \%$ ratio for managers - supervisors - staff as shown on the table below. A - H represents the 8 organisations and the figures represent the total percentage of respondents for each of the organisation.

Table 3 - Demographic Spread based on Responsibilities

\begin{tabular}{|c|c|c|c|c|c|c|c|c|c|c|}
\hline \multicolumn{10}{|c|}{ RESPONSIBILITIES } \\
\hline & $\mathrm{A}$ & $\mathrm{B}$ & $\mathrm{C}$ & $\mathrm{D}$ & $\mathrm{E}$ & $\mathrm{F}$ & $\mathrm{G}$ & $\mathrm{H}$ & Total & Average \\
\hline Shop Floor & $57.50 \%$ & $40.00 \%$ & $56.67 \%$ & $50.00 \%$ & $46.00 \%$ & $40.00 \%$ & $50.00 \%$ & $42.86 \%$ & $383.02 \%$ & $48 \%$ \\
\hline Supervisors & $30.00 \%$ & $40.00 \%$ & $33.33 \%$ & $33.33 \%$ & $40.00 \%$ & $40.00 \%$ & $40.00 \%$ & $42.86 \%$ & $299.52 \%$ & $37 \%$ \\
\hline Managers & $12.50 \%$ & $20.00 \%$ & $10.00 \%$ & $16.67 \%$ & $14.00 \%$ & $20.00 \%$ & $10.00 \%$ & $14.29 \%$ & $117.45 \%$ & $15 \%$ \\
\hline Total & $100.00 \%$ & $100.00 \%$ & $100.00 \%$ & $100.00 \%$ & $100.00 \%$ & $100.00 \%$ & $100.00 \%$ & $100.00 \%$ & & $100 \%$ \\
\hline
\end{tabular}


There was also a fairly average even split among the various demographics in terms of the years of experience.

The service organisations $\mathrm{G}$ and $\mathrm{H}$ however had very little representation in the medium to higher experience groups. This was probably due to weaker compensation and welfare packages in these organisations and is perhaps worth a further research.

Table 4 - Demographic Spread based on Years of Experience

\begin{tabular}{|c|c|c|c|c|c|c|c|c|c|c|}
\hline \multicolumn{9}{|c|}{ YEARS OF EXPERIENCE } \\
\hline & $\mathrm{A}$ & $\mathrm{B}$ & $\mathrm{C}$ & $\mathrm{D}$ & $\mathrm{E}$ & $\mathrm{F}$ & $\mathrm{G}$ & $\mathrm{H}$ & Total & Average \\
\hline$>\mathbf{2 5}$ & $17.50 \%$ & $12.50 \%$ & $16.67 \%$ & $23.33 \%$ & $20.00 \%$ & $4.00 \%$ & $0.00 \%$ & $0.00 \%$ & $94.00 \%$ & $11.75 \%$ \\
\hline $\mathbf{1 5 - 2 5}$ & $30.00 \%$ & $27.50 \%$ & $43.33 \%$ & $26.67 \%$ & $18.00 \%$ & $8.00 \%$ & $6.00 \%$ & $1.43 \%$ & $160.93 \%$ & $20.12 \%$ \\
\hline$>\mathbf{7}<\mathbf{1 5}$ & $17.50 \%$ & $35.00 \%$ & $20.00 \%$ & $26.67 \%$ & $32.00 \%$ & $28.00 \%$ & $18.00 \%$ & $2.86 \%$ & $180.03 \%$ & $22.50 \%$ \\
\hline $\mathbf{3 - 7}$ Yrs & $17.50 \%$ & $15.00 \%$ & $16.67 \%$ & $16.67 \%$ & $18.00 \%$ & $38.00 \%$ & $40.00 \%$ & $54.29 \%$ & $216.12 \%$ & $27.01 \%$ \\
\hline$<\mathbf{3}$ & $17.50 \%$ & $10.00 \%$ & $3.33 \%$ & $6.67 \%$ & $12.00 \%$ & $22.00 \%$ & $36.00 \%$ & $41.43 \%$ & $148.93 \%$ & $18.62 \%$ \\
\hline & & & & & & & & & & $100.00 \%$ \\
\hline
\end{tabular}

Tables 5 to 9 show the results of the survey based the five HRO principles. Columns A to H represent the eight organisations, while the figures represent the generalized average for each organisation for each response level. Considering the respondents' assessment of their organisations' preoccupation with failure, company A at 74.17\% mostly showed the behaviours expected from HROs. All the other organisations exhibited behaviours indicative of varying levels of maturity. Similar results were obtained when assessing the responses based on the other HRO principles as shown in tables $6,7,8$, and 9.

Table 5 - Assessing Preoccupation with Failure

\begin{tabular}{|c|c|c|c|c|c|c|c|c|c|c|}
\hline \multicolumn{10}{|c|}{ PREOCCUPATION WITH FAILURE } & F \\
\hline & A & B & C & D & E & F & G & H & & Average \\
\hline Strongly Agree & 74.17 & 7.50 & 7.56 & 1.11 & 2.80 & 0.27 & 0.00 & 0.00 & 93.40 & $\mathbf{1 1 . 6 8}$ \\
\hline Partially Agree & 11.33 & 25.83 & 20.44 & 23.56 & 7.33 & 3.07 & 2.53 & 0.76 & 94.86 & $\mathbf{1 1 . 8 6}$ \\
\hline Neither Agree nor Disasgree & 9.83 & 33.67 & 38.44 & 35.78 & 17.33 & 16.93 & 13.73 & 9.52 & 175.25 & $\mathbf{2 1 . 9 1}$ \\
\hline Partially Disgree & 4.67 & 17.50 & 22.22 & 26.22 & 24.80 & 38.93 & 37.47 & 40.67 & 212.48 & $\mathbf{2 6 . 5 6}$ \\
\hline Strongly Disagree & 0.00 & 15.50 & 11.33 & 13.33 & 47.73 & 40.80 & 46.27 & 49.05 & 224.01 & $\mathbf{2 8 . 0 0}$ \\
\hline Total & 100.00 & 100.00 & 100.00 & 100.00 & 100.00 & 100.00 & 100.00 & 100.00 & & $\mathbf{1 0 0 . 0 0}$ \\
\hline
\end{tabular}

Table 6 - Assessing Reluctance to Simplify

\begin{tabular}{|c|c|c|c|c|c|c|c|c|c|c|}
\hline \multicolumn{11}{|c|}{ RELUCTANCE TO SIMPLIFY } \\
\hline & $\mathrm{A}$ & $\mathrm{B}$ & $\mathrm{C}$ & $\mathrm{D}$ & $\mathrm{E}$ & F & $\mathrm{G}$ & $\mathrm{H}$ & & Average \\
\hline Strongly Agree & 91.46 & 15.63 & 0.28 & 5.56 & 2.83 & 2.50 & 0.00 & 0.00 & 118.25 & 14.78 \\
\hline Partially Agree & 8.54 & 22.71 & 16.94 & 18.89 & 23.00 & 12.83 & 3.67 & 3.33 & 109.92 & 13.74 \\
\hline Neither Agree nor Disasgree & 0.00 & 30.21 & 30.00 & 25.56 & 32.83 & 28.00 & 28.50 & 27.98 & 203.07 & 25.38 \\
\hline Partially Disgree & 0.00 & 24.79 & 35.83 & 28.89 & 27.17 & 32.83 & 41.00 & 43.93 & 234.44 & 29.31 \\
\hline Strongly Disagree & 0.00 & 6.67 & 16.94 & 21.11 & 14.17 & 23.83 & 26.83 & 24.76 & 134.32 & 16.79 \\
\hline Total & 100.00 & 100.00 & 100.00 & 100.00 & 100.00 & 100.00 & 100.00 & 100.00 & & 100.00 \\
\hline
\end{tabular}

Table 7 - Assessing Sensitivity to Operations

\begin{tabular}{|c|c|c|c|c|c|c|c|c|c|c|}
\hline \multicolumn{11}{|c|}{ SENSITIVITY TO OPERATIONS } \\
\hline Strongly Agree & A & $\mathrm{B}$ & $\mathrm{C}$ & $\mathrm{D}$ & $\mathrm{E}$ & $\mathrm{F}$ & $\mathrm{G}$ & $\mathrm{H}$ & & Average \\
\hline Strongly Agree & 86.82 & 19.77 & 8.48 & 20.00 & 8.73 & 5.64 & 0.18 & 0.91 & 150.53 & 18.82 \\
\hline Partially Agree & 9.09 & 27.05 & 24.85 & 32.12 & 23.82 & 18.36 & 6.91 & 7.14 & 149.34 & 18.67 \\
\hline Neither Agree nor Disasgree & 2.27 & 32.50 & 35.76 & 20.30 & 28.18 & 24.91 & 31.45 & 26.88 & 202.26 & 25.28 \\
\hline Partially Disgree & 1.82 & 15.68 & 25.15 & 16.97 & 24.91 & 28.55 & 38.36 & 40.00 & 191.44 & 23.93 \\
\hline Strongly Disagree & 0.00 & 5.00 & 5.76 & 10.61 & 14.36 & 22.55 & 23.09 & 25.06 & 106.43 & 13.30 \\
\hline Total & 100.00 & 100.00 & 100.00 & 100.00 & 100.00 & 100.00 & 100.00 & 100.00 & & 100.00 \\
\hline
\end{tabular}


Table 8 - Assessing Commitment to Resilience

\begin{tabular}{|c|c|c|c|c|c|c|c|c|c|c|}
\hline \multicolumn{11}{|c|}{ COMMITMENT TO RESILIENCE } \\
\hline & $\mathrm{A}$ & $\mathrm{B}$ & $\mathrm{C}$ & $\mathrm{D}$ & E & $\mathrm{F}$ & $\mathrm{G}$ & $\mathrm{H}$ & & Average \\
\hline Strongly Agree & 95.63 & 30.63 & 5.00 & 16.39 & 13.50 & 6.33 & 0.17 & 0.48 & 168.12 & 21.01 \\
\hline Partially Agree & 2.50 & 37.92 & 28.33 & 15.28 & 28.17 & 22.33 & 13.33 & 5.83 & 153.69 & 19.21 \\
\hline Neither Agree nor Disasgree & 1.46 & 21.25 & 41.94 & 36.11 & 39.50 & 25.17 & 26.00 & 16.67 & 208.10 & 26.01 \\
\hline Partially Disgree & 0.42 & 8.33 & 17.50 & 26.11 & 18.17 & 29.00 & 34.67 & 37.14 & 171.34 & 21.42 \\
\hline Strongly Disagree & 0.00 & 1.88 & 7.22 & 6.11 & 0.67 & 17.17 & 25.83 & 39.88 & 98.76 & 12.34 \\
\hline Total & 100.00 & 100.00 & 100.00 & 100.00 & 100.00 & 100.00 & 100.00 & 100.00 & & 100.00 \\
\hline
\end{tabular}

Table 9 - Assessing Commitment to Resilience

\begin{tabular}{|c|c|c|c|c|c|c|c|c|c|c|}
\hline \multicolumn{11}{|c|}{ DEFERENCE TO EXPERTISE } \\
\hline & $\mathrm{A}$ & $\mathrm{B}$ & $\mathrm{C}$ & $\mathrm{D}$ & $\mathrm{E}$ & $\mathrm{F}$ & $\mathrm{G}$ & $\mathrm{H}$ & & Average \\
\hline Strongly Agree & 96.88 & 6.25 & 1.67 & 11.25 & 4.00 & 6.75 & 0.50 & 0.00 & 127.29 & 15.91 \\
\hline Partially Agree & 3.13 & 15.63 & 12.08 & 17.08 & 16.50 & 17.75 & 11.25 & 1.61 & 95.02 & 11.88 \\
\hline Neither Agree nor Disasgree & 0.00 & 17.81 & 19.17 & 20.83 & 22.50 & 21.75 & 22.75 & 22.50 & 147.31 & 18.41 \\
\hline Partially Disgree & 0.00 & 25.31 & 26.25 & 23.75 & 24.75 & 23.75 & 26.00 & 32.50 & 182.31 & 22.79 \\
\hline Strongly Disagree & 0.00 & 35.00 & 40.83 & 27.08 & 32.25 & 30.00 & 39.50 & 43.39 & 248.06 & 31.01 \\
\hline Total & 100.00 & 100.00 & 100.00 & 100.00 & 100.00 & 100.00 & 100.00 & 100.00 & & 100.00 \\
\hline
\end{tabular}

Another observation was perhaps the obvious schism between the responses of the different strata of the organisations, and that this is common among all the organisations further strengthens the reliability of the research. For instance, when considering preoccupation with failure in organisation B, all managers chose option 3 and above for the question "we do not victimize people who make mistakes" while all the respondents on the shop floor chose options 2 and below. Similarly, for the communication comments such as "we feel free to talk to our superiors"; our superiors freely talk to us about our problems; and "our superiors actively seek out bad news about potential issues", all the managers chose options 3 and above. On the other hand, all the respondents on the shop floor chose options 3 and below; with $90 \%$ of them disagreeing partially or fully. This was a common observation in all the HRO principles and in all the organisations studied. This schism indicates a huge gap between the different strata of the organisations, both in terms of communicating, understanding, and implementing the processes required to exhibit the high reliability behaviours and should therefore be considered during the implementation of the maturity framework.

The results from the semi structured interviews helped understand the reasons the survey results. This understanding would help in the development and implementation of the framework and in its application organisational improvement.

\subsection{Reliability and validity}

The research ensured reliability by the simplicity and clarity of the wordings so that the meanings would remain 
the same with different respondents. To verify this, responses within similar strata in the same organisation were mostly similar and consistent. Responses in alternative forms of questions introduced at random throughout the questionnaire were also mostly similar. Table 10 shows a comparison of the alternative forms 'we have well defined emergency plans' and 'we have well defined contingency plans' in the commitment to resilience section. A well-developed emergency response plan would normally have a well-developed contingency plan and as such similar responses was expected, and mostly similar responses were obtained.

Table 10 - Comparison of the results from the emergency/contingency check questions

\begin{tabular}{|c|c|c|}
\hline & Availability of defined emergency plan & Availability of defined contingency plan \\
\hline Company A & $100 \%$ at level 5 & $100 \%$ at level 5 \\
\hline Company B & $100 \%$ at levels $4 \& 5$ & $100 \%$ at levels $4 \& 5$ \\
\hline Company $\mathrm{C}$ & $100 \%$ at levels $4 \& 5$ & $100 \%$ at levels $4 \& 5$ \\
\hline Company D & $100 \%$ at levels $4 \& 5$ & $100 \%$ at levels $4 \& 5$ \\
\hline Company E & $32 \%(5), 30 \%(4), 26 \%(3), 12 \%(2), 0 \%(1)$ & $32 \%(5), 30 \%(4), 26 \%(3), 12 \%(2), 0 \%(1)$ \\
\hline Company F & $100 \%$ at levels $1-3,78 \%$ of which are at levels $1-2$. & $100 \%$ at levels $1-3,88 \%$ of which are at levels $1-2$. \\
\hline Company G & $100 \%$ at levels $1-3$ & $100 \%$ at levels $1-3$ \\
\hline Company $\mathrm{H}$ & $0 \%(5), 0 \%(4), 8 \%(3), 38 \%(2), 54 \%(1)$ & $0 \%(5), 0 \%(4), 8 \%(3), 38 \%(2), 54 \%(1)$ \\
\hline
\end{tabular}

A similar result was obtained from all the alternative forms including in the deference to expertise section as shown in table 11 for the questions: 'people in the organisation value expertise over rank' and 'we are expected to take expert decisions irrespective of position or rank'.

Table 11 - Comparison of the results from the expertise over rank check questions

\begin{tabular}{|l|l|l|}
\hline & Value expertise over rank & Expert decisions irrespective of position or rank \\
\hline Company A & $100 \%$ at level 5 & $100 \%$ at level 5 \\
\hline Company B & $100 \%$ at level $1 \& 2$ & $90 \%$ at level $1 \& 2$ \\
\hline Company C & $0 \%(5), 0 \%(4), 6.67 \%(3), 36.6 \%(2), 56.6 \%(1)$ & $0 \%(5), 0 \%(4), 6.67 \%(3), 36.6 \%(2), 56.6 \%(1)$ \\
\hline Company D & $100 \%$ at level $1 \& 2$ & $87 \%$ at level $1 \& 2$ \\
\hline Company E & $100 \%$ at level $1 \& 2$ & $82 \%$ at level $1 \& 2$ \\
\hline Company F & $100 \%$ at level $1 \& 2$ & $92 \%$ at level 1 \& 2 \\
\hline Company G & $100 \%$ at level $1 \& 2$ & $97 \%$ at level $1 \& 2$ \\
\hline Company H & $100 \%$ at level $1 \& 2$ & $96 \%$ at level $1 \& 2$ \\
\hline
\end{tabular}

\subsection{The Framework}

\subsection{The Organisational Reliability Maturity Model $\left(\mathrm{ORM}^{2}\right)$}

The first step towards maturing organisations towards reliability would be to develop an objective and measureable framework to measure organisational reliability. As a popular adage goes, “you can't manage what you can't measure", or as some others choose to put it, "you can't improve what you can't measure". The research developed the organisational reliability maturity model $\left(\mathrm{ORM}^{2}\right)$, as a $5 S$ model that tracks the progression of organisations through 5 maturity levels (table 12). $5 S$ here refers to the five maturity stages: silent, starter, stable, sustain, and summit. ORM ${ }^{2}$ comprises of 25 boxes containing 25 sets of organisational 
reliability behaviours. The maturity levels are on the $\mathrm{x}$-axis with incremental maturity behaviours as the boxes progress towards the right hand side. The y-axis represents the five HRO principles. This means that for each HRO principle, there are five sets of organisational reliability behaviours, with incremental improvements as the levels increase from level 1 (silent) towards level 5 (summit). The model begins with a "silent" period (level 1), a passive period characterised by lack of standardized processes, poor communication, inadequate procedures, combative and punitive relationships, and a false sense of safety and security - an 'if it ain't broke, don't fix it mentality". As the organisation begins to realise the dangers of remaining in a "silent" period, it begins to develop some processes. It also begins to take steps towards improving communication, developing procedures, trainings, and competence development exercises. It begins to encourage near miss and incident reporting. The organisation at this stage is considered a "starter" and is said to have begun its teething process. At a point, the processes and procedures for most jobs and will become fully developed and everyone will understand and work the process with an almost mechanical precision. People comply because they have to. In most cases, the organisation would have slogans such as "if you decide not to comply with the process, you have decided not to work with us". The emphasis is clear: comply or be sacked, and people are therefore compelled to comply. Employees would attend meetings at regular times because they have to, attend trainings because they have to, and participate in appraisals because they must. This is the "stable" stage, where the organisation is expected to be fully standardized and working with clockwork efficiency.

At level 4, "sustain", the people begin to understand and agree with the reasons for the processes and procedures and actually begin to take the initiative to own the process. They begin to see themselves as stakeholders to help sustain the process. An emergency drill will no longer be seen as a necessary burden to please the leaders, but as a necessary tool towards personal and organisational resilience. People begin to own their learning and development and would begin to see feedback as a positive process for organisational and personal improvement. The organisation would begin to proactively feed lessons learned back into the process to improve it. The organisation begins to value and reward sceptics and those that think outside the box and meetings will begin to become useful avenues for improvement discussions. The final level is the "summit", a stage where the relationships between the leaders and the led, and among the people in the organisation becomes very respectful, people actively seek 360 degrees feedback and accept the objective feedback as a performance improvement opportunity. People are mindful of the operations and take proactive decisions to safeguard and improve the process. Everyone works proactively without coercion, with a common purpose to improve and sustain the organisation. Organisations in level five are highly reliable and the behaviours included here are 
selected based on numerous previous HRO studies. ORM ${ }^{2}$ sets out the expected behaviours for each maturity level. It becomes more useful when applied with the measureable framework for organisational reliability maturity (FORM). The elements that enhance mindfulness are not exhaustive, therefore the elements included within each maturity stage under each HRO principle (table 12) is not exhaustive. Industries could use this framework and extend mindfulness behaviours specific to such industry. 
Table 12: Organisational Reliability Maturity Model $\left(\mathrm{ORM}^{2}\right)-$ The $5 \mathrm{~S}$ Model

\begin{tabular}{|c|c|c|c|c|c|}
\hline \multicolumn{6}{|c|}{ ORGANIZATIONAL RELIABILITY MATURITY MODEL } \\
\hline & Level 1 (Silent) & Level 2 (Starter) & Level3 (Stable) & Level 4 (Sustain) & Level 5 (Summit) \\
\hline $\begin{array}{l}\text { Preoccupation } \\
\text { with Failure }\end{array}$ & \begin{tabular}{|l|} 
Failure/Near Misses are not reported. \\
Punishment for people that cause incidents. \\
Management difficult to approach. \\
Continuous mindset that failure will not \\
happen. If a failure occurs, someone is always \\
to blame.
\end{tabular} & $\begin{array}{l}\text { Failure/Near misses sometimes reported and } \\
\text { rectified. Root causes may not be identified. } \\
\text { People that cause incidents are perceived as } \\
\text { incompetent but may not be punished. Some } \\
\text { communication with a few people. }\end{array}$ & \begin{tabular}{|l|} 
Failure/Near misses reporting process exists and \\
is generally enforced. Root causes identified. \\
People often blamed. Superiors communicates \\
with frontline to give clear instructions.
\end{tabular} & $\begin{array}{l}\text { Failure/Near misses reported. Root causes identified and } \\
\text { people not blamed. Clear and open communications. } \\
\text { Worst case scenarios considered in planning. Lessons } \\
\text { learned documented. }\end{array}$ & $\begin{array}{l}\text { Failure/Near Miss identified, categorized, documented. } \\
\text { Root causes identified. Root causes resolved with no } \\
\text { blame on people. Lessons learned reviewed periodically } \\
\text { and used to improve the system. People that report near } \\
\text { missesffailure are actively rewarded. Superiors actively } \\
\text { seek out bad news. Clear and open communication } \\
\text { between superiors and front line staff. Planning } \\
\text { considers worst case scenarios. Continuous reviews to } \\
\text { seek out hot spots. }\end{array}$ \\
\hline $\begin{array}{l}\text { Reluctance to } \\
\text { Simplify }\end{array}$ & $\begin{array}{l}\text { Skeptics and people that challenge the norm } \\
\text { are mostly victimized and punished as } \\
\text { disruptors. }\end{array}$ & $\begin{array}{l}\text { Skeptics and people who challenge the norm } \\
\text { may not be punished, but may be viewed } \\
\text { negatively }\end{array}$ & $\begin{array}{l}\text { A process for challenging the process exists. It } \\
\text { is ok to challenge the norm. Implementation } \\
\text { may be delayed by layers of bureaucracy. }\end{array}$ & $\begin{array}{l}\text { Views from skeptics and out of the box thinkers are } \\
\text { respected and often implemented by management. }\end{array}$ & $\begin{array}{l}\text { Management actively creates forums for people to } \\
\text { challenge the norm and out of the box thinkers are } \\
\text { rewarded. }\end{array}$ \\
\hline $\begin{array}{l}\text { Sensitivity to } \\
\text { Operations }\end{array}$ & $\begin{array}{l}\text { Meetings are rare without quality: no focus } \\
\text { on long/short term team/organization. } \\
\text { Leaders are unaware of frontline issues. } \\
\text { People generally do not understand jobs } \\
\text { outside their specialty. Feedback is viewed as } \\
\text { a process of negative reinforcement. There is } \\
\text { no feedback process. People are generally } \\
\text { overworked and stressed out. Complaints are } \\
\text { viewed as insubordination and could be } \\
\text { punished }\end{array}$ & $\begin{array}{l}\text { Occasional meetings with no defined terms of } \\
\text { reference. Leaders request for and receive } \\
\text { reports as desired. People may understand jobs } \\
\text { outside their competencies, but rarely get } \\
\text { involved. People generally do not care about } \\
\text { feedback. Might receive one during annual } \\
\text { appraisal. There are occasional breaks to relieve } \\
\text { work stress }\end{array}$ & \begin{tabular}{|l|} 
Regular Meetings with defined terms of \\
reference. A clearly defined work report \\
process exists and is enforced. A formal process \\
exists and is generally enforced for people to \\
learn jobs outside their competencies and get \\
involved. A feedback process exists and is \\
generally enforced. There is a process to \\
manage workloads
\end{tabular} & $\begin{array}{l}\text { Regular Meetings are regular with defined terms of } \\
\text { reference and individual roles/responsibilities. Leaders } \\
\text { generally get involved in the frontline day to day } \\
\text { activities and therefore receive first hand reports. } \\
\text { People are generally willing to get involved in jobs } \\
\text { outside their competencies and the opportunities exist } \\
\text { for them to do so. People generally give and receive } \\
\text { feedback at defined times without coercion. Leaders } \\
\text { continuously monitor workloads and add resources as } \\
\text { required. }\end{array}$ & $\begin{array}{l}\text { Meetings are regular with defined terms of reference and } \\
\text { individual rolessresponsibilities. It is clear how } \\
\text { everyone's roles fits into the big picture. Frontline and } \\
\text { leaders are generally free with one another and interact } \\
\text { freely in day to day operations. People are rewarded for } \\
\text { getting involved in jobs outside their competencies. } \\
\text { People actively seek feedback, and perceive } 360^{*} \\
\text { feedback as constructive exercises. Leaders continuously } \\
\text { work with staff to monitor workloads and would } \\
\text { collectively determine need for additional resources. }\end{array}$ \\
\hline $\begin{array}{l}\text { Commitment to } \\
\text { Resilience }\end{array}$ & $\begin{array}{l}\text { The company does not organize/sponsor } \\
\text { trainings. Competencies and skills are not } \\
\text { assessed. There are no emergency response } \\
\text { and contingency plans. }\end{array}$ & $\begin{array}{l}\text { Trainings exist, but only used to reward favoured } \\
\text { staff. Individual leaders assess competencies and } \\
\text { skills in their own way. There are emergency } \\
\text { response and contingency plans but people are } \\
\text { generally not aware of them. Drills are regarded } \\
\text { as nuisance. }\end{array}$ & \begin{tabular}{|l|} 
There is a formalized training and \\
competence/skills assessment for all staff and \\
the plan is generally enforced. Emergency drills \\
are done and people are mandated to \\
participate. People are generally mandated to \\
understand the emergency \\
response/contingency plans \\
\end{tabular} & $\begin{array}{l}\text { Leaders and staff work together to identify training and } \\
\text { development gaps and close them. Competence } \\
\text { assessment is an ongoing process and feedback is } \\
\text { constructive. People actively seek to understand and } \\
\text { review emergency response and contingency plans. } \\
\text { People regard drills as ways to potentially save lives } \\
\end{array}$ & $\begin{array}{l}\text { People generally have more than enough skills for their } \\
\text { jobs and to act during emergencies. Competence and } \\
\text { skills assessment is a proactive process. Emergency } \\
\text { response and contingency plans are robust and } \\
\text { implementation is a shared responsibility among all } \\
\text { staff. Everyone trusts one another and relies on one } \\
\text { another during emergencies. }\end{array}$ \\
\hline $\begin{array}{l}\text { Deference to } \\
\text { Expertise }\end{array}$ & $\begin{array}{l}\text { In an emergency, the most senior person } \\
\text { takes responsibility irrespective experience. } \\
\text { It is difficult to know who has the most } \\
\text { expertise for each emergency. }\end{array}$ & \begin{tabular}{|l|} 
People generally know who has the most \\
expertise during an emergency. Hierarchical \\
rank takes precedent during emergencies. The \\
most senior person feels insulted if not in charge \\
during emergencies.
\end{tabular} & $\begin{array}{l}\text { There is a formal process to determine who } \\
\text { takes responsibility during each emergency. }\end{array}$ & $\begin{array}{l}\text { The most senior person yields responsibility to the } \\
\text { person with the most expertise for during each } \\
\text { emergency. The expert accepts the responsibility } \\
\text { professionally and yields back after the emergency. } \\
\text { Expertise for all emergencies is readily available }\end{array}$ & $\begin{array}{l}\text { There is a mutual respect for one another's jobs. No job } \\
\text { is considered more important than the other. People are } \\
\text { encouraged to take expert decisions irrespective of } \\
\text { hierarchy during emergencies. People feel responsible } \\
\text { until problems are resolved. }\end{array}$ \\
\hline
\end{tabular}


The framework has multi-faceted features; the most significant of which is the standardized measurement for organisational reliability. With this measurement come four different functions. First, it is a health check that assesses the current maturity level of organisations. Secondly, the framework could use the current organisational reliability behaviours to predict the future direction of the organisation. The third function is the ability to benchmark organisations against desired maturity standards. The final function lies in the ability to enhance organisational learning and performance improvement. To develop FORM, the organisation must first conduct a survey using $\mathrm{ORM}^{2}$ or its variant tailored to suit organisational needs. This has been field tested in eight diverse organisations with similar results.

Using the values obtained from the survey as summarized in tables 5 to 9 , Table 13 shows FORM table for company C. All subsequent tables will pull data from tables 5 to 9 , which is the summary of the research data.

Table 13: Framework for Organisational Reliability Maturity (FORM)

\begin{tabular}{|c|c|c|c|c|c|c|c|}
\hline \multicolumn{7}{|c|}{ COMPANY C (OIL \&GAS)) } & (Sensitivity to \\
\hline Level & $\begin{array}{c}\text { Preoccupation with } \\
\text { Failure }\end{array}$ & $\begin{array}{c}\text { Reluctance to } \\
\text { Simplify }\end{array}$ & $\begin{array}{c}\text { Operations } \\
\text { Resilience }\end{array}$ & $\begin{array}{c}\text { Deference to } \\
\text { Expertise }\end{array}$ & $\begin{array}{c}\text { Average } \\
\text { Score }\end{array}$ & Pull \\
\hline $\mathbf{5}$ & 7.56 & 0.28 & 8.48 & 5.00 & 1.67 & $\mathbf{4 . 6 0}$ & 0.14 \\
\hline $\mathbf{4}$ & 20.44 & 16.94 & 24.85 & 28.33 & 12.08 & $\mathbf{2 0 . 5 3}$ & 0.62 \\
\hline $\mathbf{3}$ & 38.44 & 30.00 & 35.76 & 41.94 & 19.17 & $\mathbf{3 3 . 0 6}$ & 0.00 \\
\hline $\mathbf{2}$ & 22.22 & 35.83 & 25.15 & 17.50 & 26.25 & $\mathbf{2 5 . 3 9}$ & 0.77 \\
\hline $\mathbf{1}$ & 11.33 & 16.94 & 5.76 & 7.22 & 40.83 & $\mathbf{1 6 . 4 2}$ & 0.50 \\
\hline
\end{tabular}

The five HRO principles are mapped into five levels that correspond with the five maturity levels on the Organisational Reliability Maturity Model $\left(\mathrm{ORM}^{2}\right)$. The values corresponding with each HRO principle is the average percentage score for all the respondents in each of the five maturity levels and sums up to $100 \%$. The levels on the other hand correspond with the selections 1 to 5 on the questionnaire. This means that for this organisation, $7.56 \%$ of the respondents consider the organisation to exhibit the maturity level 5 behaviours in their preoccupation with failure. $40.83 \%$ on the other hand consider the organisation to be at maturity level 1 in their deference to expertise behaviours. Maturity levels could be determined at individual HRO principle level or at the general organisation level. The maturity of the organisation is determined by the level with the highest average score. The average score column is a simple average of responses from the five HRO principles in each maturity level. With $33.06 \%$ as the highest average score, company C is considered to be at maturity level 3 (stable). The performance in each of five principles could give an indication of how much resources the organisation could commit to one principle over the others to achieve improvement. 
The last column is the pull, and it indicates the maturity level where the organisation has the most potential of slipping into given prevailing conditions. Pull (P) is a simple probability:

$$
\boldsymbol{P}=\mathbf{1}-(\boldsymbol{R}-\boldsymbol{R} \boldsymbol{i}) / \boldsymbol{R}
$$

$\mathrm{R}$ is the average score for the assigned maturity level of the organisation, while $R i$ is the average score for the maturity level under consideration. For Table 13, 33.06\% is the highest average score $R$. Considering level 5 (summit), the average score $R i$ is $4.6 \%$. Substituting $R$ and $R i$ in the pull calculation above, the pull towards level 5 (summit) will be 0.14 . The same process is applied to other maturity level to obtain their pull. From these calculations, the pull is highest towards maturity level 2 (starter) at 0.77 . This means that the organisation has the highest probability of slipping into a level 2 (starter) from its current maturity level 3 (stable), given its prevailing organisational reliability behaviours. There is an equally strong pull towards level $1($ silent $)$ at 0.50 and organisation must be careful not only to slide into level 2 (starter), but could potentially move further down towards level 1(silent). 0.5 is considered the low pull, while 0.77 is considered the high pull. The framework shows that the higher the pull, the more the probability of the organisation to move towards that maturity level. In addition to applying the pull to the entire organisation considering the averages of the HRO principles, it can be applied to each HRO principle to determine its potential risk factors to the organisation.

Table 14: Framework for Organisational Reliability Maturity (FORM) for individual HRO principles

\begin{tabular}{|c|c|c|c|c|c|}
\hline \multicolumn{7}{|c|}{ FRAMEWORK FOR ORGANISATIONAL RELIABILITY MATURITY } \\
\hline \multicolumn{7}{|c|}{ COMPANY C (OIL \&GAS)) } \\
\hline Level & $\begin{array}{c}\text { Preoccupation with } \\
\text { Failure }\end{array}$ & Pull & $\begin{array}{c}\text { Commitment to } \\
\text { Resilience }\end{array}$ & Pull & $\begin{array}{c}\text { Average Pull for } \\
\text { all 5 Principles }\end{array}$ \\
\hline $\mathbf{5}$ & 7.56 & 0.20 & 5.00 & 0.12 & 0.11 \\
\hline $\mathbf{4}$ & 20.44 & 0.53 & 28.33 & 0.68 & 0.60 \\
\hline $\mathbf{3}$ & 38.44 & 0.00 & 41.94 & 0.00 & 0.00 \\
\hline $\mathbf{2}$ & 22.22 & 0.58 & 17.50 & 0.42 & 0.77 \\
\hline $\mathbf{1}$ & 11.33 & 0.29 & 7.22 & 0.17 & 0.50 \\
\hline
\end{tabular}

In table 14 above, the pull is applied to the preoccupation to failure and the commitment to resilience principles. Company $\mathrm{C}$ is at maturity level 3 (stable) on both principles but is being pulled differently on both. It is strongly pulled at 0.58 down towards level 2 (starter) in preoccupation to failure, and at 0.68 up towards level 4 (sustain) in commitment to resilience. The pull in this instance could help the organisation prioritize resources to achieve a higher overall maturity level. The sum of all the values in each HRO principle, as well as the sum of the 
average scores should always be $100 \%$. All numbers, except the pull, are percentages of responses. The next section describes the various applications of FORM and ORM².

\subsection{Applications of FORM and ORM²}

\subsection{Assessing organisations}

Table 15 shows organisation $\mathrm{H}$ to be at maturity level 2 (starter), with an average score of $38.85 \%$. It also shows the individual strengths and weaknesses of the organisation with respect to each of the five HRO principles. It show for instance that although " $\mathrm{H}$ " is generally at maturity level 2 (starter), it is at level 1 (silent) in its preoccupation with failure, commitment to resilient, and deference to expertise behaviours. The framework therefore helps organisations to perform a health check. ' $H$ ' would observe the very thin line between its level 2 and level 1 positions, where it could easily slide from one to the other. It would also understand the need to improve its performances in preoccupation with failure, commitment to resilience, and deference to expertise. With this measurement, the organisation could then begin to develop improvement measures.

Table 15: Framework for Organisational Reliability Framework (FORM) for Company H

\begin{tabular}{|c|c|c|c|c|c|c|c|}
\hline \multicolumn{7}{|c|}{ FRAMEWORK FOR ORGANISATIONAL RELIABILITY } & \multirow[b]{3}{*}{ Pull } \\
\hline \multicolumn{7}{|c|}{ COMPANY H (RESTAURANT CHAIN) } & \\
\hline Level & \begin{tabular}{|c|} 
Preoccupation with \\
Failure
\end{tabular} & $\begin{array}{c}\text { Reluctance to } \\
\text { Simplify }\end{array}$ & $\begin{array}{l}\text { Sensitivity to } \\
\text { Operations }\end{array}$ & $\begin{array}{c}\text { Commitment to } \\
\text { Resilience }\end{array}$ & $\begin{array}{c}\text { Deference to } \\
\text { Expertise }\end{array}$ & $\begin{array}{c}\text { Average } \\
\text { Score } \\
\end{array}$ & \\
\hline 5 & 0.00 & 0.00 & 0.91 & 0.48 & 0.00 & 0.28 & 0.01 \\
\hline 4 & 0.76 & 3.33 & 7.14 & 5.83 & 1.61 & 3.74 & 0.10 \\
\hline 3 & 9.52 & 27.98 & 26.88 & 16.67 & 22.50 & 20.71 & 0.53 \\
\hline 2 & 40.67 & 43.93 & 40.00 & 37.14 & 32.50 & 38.85 & 0.00 \\
\hline 1 & 49.05 & 24.76 & 25.06 & 39.88 & 43.39 & 36.43 & 0.94 \\
\hline
\end{tabular}

\subsection{Predicting the future and preventing potential disasters}

Being able to predict the future is the elusive crystal ball that all have desired and few have achieved. This framework utilizes the $\mathrm{ORM}^{2}$ and the assessment in section 5.1 to predict future behaviour of the organisations. Organisations with lower maturity levels have weaker organisational reliability behaviours, and are potentially more prone to disasters Perhaps, understanding such future behaviour could potentially become the key to incident prevention. Using company G as an example (table 16), the organisation currently on maturity level 2 (starter), could potentially retrogress to maturity level 1(silent) if it continues with its current behavioural trends. The pull of 0.91 towards level 1 (silent) is very strong and would more likely cause the organisation to retrogress towards level 1 than improve towards level 3 where the pull is 0.69 . This suggests that given current practices, the organisation is an "accident waiting to happen" with an increasing potential for an incident. 
Table 16: Framework for Organisational Reliability Framework (FORM) for Company G

\begin{tabular}{|c|c|c|c|c|c|c|c|}
\hline \multicolumn{7}{|c|}{ COMPANY G (RESTAURANT CHAIN) } & \\
\hline Level & $\begin{array}{c}\text { Preoccupation with } \\
\text { Failure }\end{array}$ & $\begin{array}{c}\text { Reluctance to } \\
\text { Simplify }\end{array}$ & $\begin{array}{c}\text { Sensitivity to } \\
\text { Operations }\end{array}$ & $\begin{array}{c}\text { Commitment to } \\
\text { Resilience }\end{array}$ & $\begin{array}{c}\text { Deference to } \\
\text { Expertise }\end{array}$ & $\begin{array}{c}\text { Average } \\
\text { Score }\end{array}$ & Pull \\
\hline $\mathbf{5}$ & 0.00 & 0.00 & 0.18 & 0.17 & 0.50 & $\mathbf{0 . 1 7}$ & 0.00 \\
\hline $\mathbf{4}$ & 2.53 & 3.67 & 6.91 & 13.33 & 11.25 & $\mathbf{7 . 5 4}$ & 0.21 \\
\hline $\mathbf{3}$ & 13.73 & 28.50 & 31.45 & 26.00 & 22.75 & $\mathbf{2 4 . 4 9}$ & 0.69 \\
\hline $\mathbf{2}$ & 37.47 & 41.00 & 38.36 & 34.67 & 26.00 & $\mathbf{3 5 . 5 0}$ & 0.00 \\
\hline $\mathbf{1}$ & 46.27 & 26.83 & 23.09 & 25.83 & 39.50 & $\mathbf{3 2 . 3 0}$ & 0.91 \\
\hline
\end{tabular}

This predictive feature is much more useful when utilized at the level of individual HRO principles. The organisation is already at the lowest level in its preoccupation with failure and deference to expertise. This means that near misses and incidents are not reported, and that the communication line between management and frontline is very difficult at best. It also means that expertise is often sacrificed on the altar of hierarchy. Combining these behaviours suggests that a disaster could be imminent. The potential is not only very high; the ability of the organisation to manage the disaster when it occurs is very low. On the other hand, the organisation could be predicted to improve to level 3 (stable) in its reluctance to simplify, sensitivity to operations, and commitment to resilience. The pull towards levels 3 and 1 in commitment to resilience are too similar that the correct prediction might be too close to call between improving towards level 3 , and retrogressing towards level 1. In such instance, it would be safe to assume a worst case scenario. From table 15, company $\mathrm{H}$ is at level 2 in its reluctance to simplify. With a strong pull towards level 1 , the organisation could be predicted to retrogress towards level 1 with a much higher probability of catastrophic incidents.

Without previous baseline data, it might be challenging to show if the pull is towards improvement of away from improvement. For instance, from table 16, the average pull of 0.91 could indicate that the current reliability behaviours are pulling the organisation towards level 1. However, an earlier pull of 0.99 towards level 1and a lower pull of 0.61 towards level 3 could indicate that the organisation is actually improving towards level 3 . This means that for an effective prediction, the baseline measurements must be established.

\subsection{Benchmarking organisations}

Organisations could use this framework to benchmark against a desired maturity level, against best in class, against peers, or for internal benchmarking. Best in class here would mean HROs. One of the first steps here would be to obtain baseline measurements using the process outlined in section 5.1. Objective data collection should not be limited to surveys but could be extended to action research and case studies based on its organisational realities. Table 17 shows a high level comparison of the 8 organisations surveyed. Black 
coloured boxes represent the current average maturity level, while grey coloured boxes represent the high pull. Assuming company A is the benchmark, all other organisations would compare their average maturity levels, as well as the levels for the individual HRO principles against company A's performance.

Table 17: Comparing average organisational maturity

\begin{tabular}{|l|c|c|c|c|c|}
\hline \multicolumn{7}{|c|}{ COMPARING THE MATURITY OF THE ORGANIZATIONS } \\
\hline ORGANIZATIONS & SILENT & STARTER & STABLE & SUSTAIN & SUMMIT \\
\hline COMPANY A & & & & & \\
\hline COMPANY B & 0.47 & 0.68 & $\mathrm{ML}$ & 0.95 & 0.59 \\
\hline COMPANY C & 0.59 & 0.77 & $\mathrm{ML}$ & 0.62 & 0.14 \\
\hline COMPANY D & 0.56 & 0.88 & $\mathrm{ML}$ & 0.77 & 0.39 \\
\hline COMPANY E & 0.77 & 0.82 & $\mathrm{ML}$ & 0.69 & 0.22 \\
\hline COMPANY F & 0.88 & $\mathrm{ML}$ & 0.76 & 0.49 & 0.14 \\
\hline COMPANY G & 0.91 & $\mathrm{ML}$ & 0.69 & 0.21 & 0 \\
\hline COMPANY H & 0.94 & $\mathrm{ML}$ & 0.53 & 0.1 & 0.01 \\
\hline
\end{tabular}

\begin{tabular}{|c|l|}
\hline LEGEND & \\
\hline & \\
\hline ML & CURRENT MATURITY LEVEL \\
\hline & HIGH PULL \\
\hline & \\
\hline & \\
\hline & \\
\hline & \\
\hline
\end{tabular}

For instance, company B has a stable organisational reliability maturity (level 3) with a pull of 0.95 towards level 4 (sustain). Similarly, companies C, D, and E have stable maturity levels (level 3) but with pulls of 0.77 , 0.88 , and 0.82 respectively towards level 2 (starter). On the other hand, companies F, G, and $\mathrm{H}$ are on maturity levels 2 , with pulls of $0.88,0.91$, and 0.94 respectively towards level 1 (silent). At a glance, each organisation could see the degree to which they are apart from the best in class. Figure 5 shows a graphical visualization of table 17.

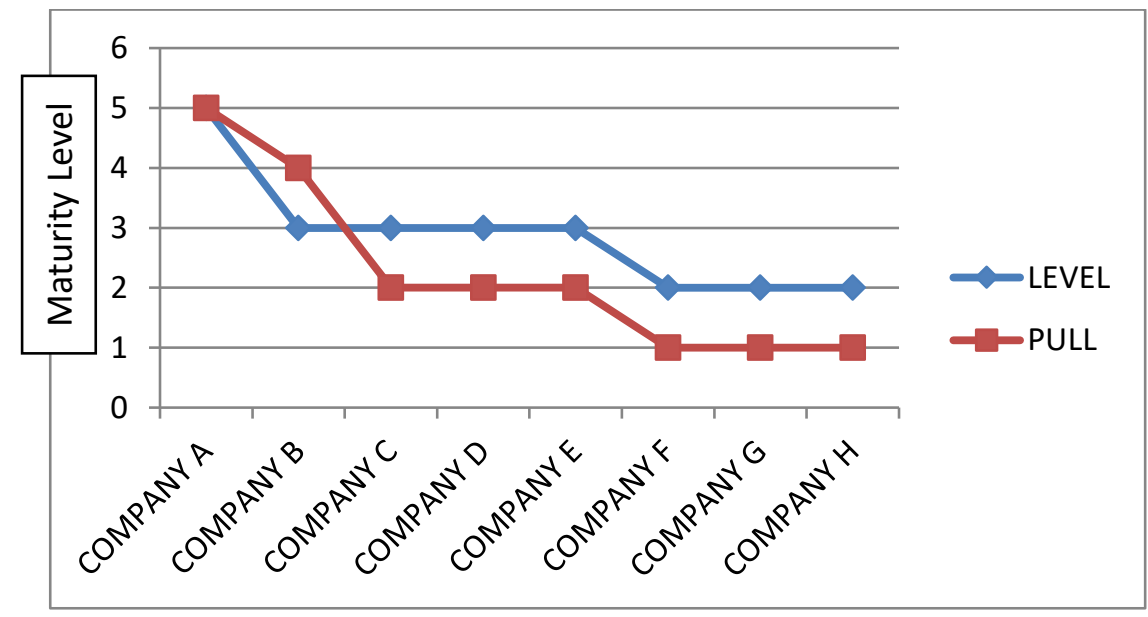

Figure 5 - A graph showing a high level comparison of the organisations

The blue curve represents the current maturity level and corresponds with the black boxes on table 17 . The red curve represents the high pull and corresponds with the grey coloured boxes in table 17. The graph simplifies the representation, while the table gives some more details. The graph easily shows that company A is more mature than $\mathrm{B}$, and $\mathrm{B}$ is more mature than $\mathrm{C}$ (because of the pull). For $\mathrm{C}, \mathrm{D}$, and $\mathrm{E}$, and $\mathrm{F}, \mathrm{G}$, and $\mathrm{H}$, the differences are not very apparent on the graph but become clearer from the details on table 17.

The framework could also provide a detailed benchmark of the individual HRO principles for the organisations as shown on table 18 and expanded further on figure 6 to figure 10. 


\begin{tabular}{|c|c|c|c|c|c|c|c|c|c|c|c|}
\hline \multicolumn{6}{|c|}{ COMPARING THE MATURITY OF THE ORGANIZATIONS } & \multicolumn{6}{|c|}{ COMPARING THE MATURITY OF THE ORGANIZATIONS } \\
\hline ORGANIZATIONS & SILENT & STARTER & TABLE & SUSTAN & SUMMIT & COMPANYE & & & & & \\
\hline COMPANYA & & & & & & Preoccupation with failure & 47.73 & 24.80 & 17.33 & 7.33 & 2.80 \\
\hline Preoccupation with failure & 0.00 & 4.67 & 9.83 & 11.33 & 74.17 & Reluctance to Simplify & 14.17 & 27.17 & 32.83 & 23.00 & 2.83 \\
\hline Reluctance to Simplify & 0.00 & 0.00 & 0.00 & 8.54 & 91.46 & Sensitivity to operations & 14.36 & 24.91 & 28.18 & 23.82 & 8.73 \\
\hline Sensitivity to operations & 0.00 & 1.82 & 2.27 & 9.09 & 86.82 & Commitment to resilience & 0.67 & 18.17 & 39.50 & 28.17 & 13.50 \\
\hline Commitment to resilience & 0.00 & 0.42 & 1.46 & 2.50 & 95.63 & Deference to expertise & 32.25 & 24.75 & 22.50 & 16.50 & 4.00 \\
\hline Deference to expertise & 0.00 & 0.00 & 0.00 & 3.13 & 96.88 & COMPANYF & & & & & \\
\hline COMPANY B & & & & & & Preoccupation with failure & 40.80 & 38.93 & 16.93 & 3.07 & 0.27 \\
\hline Preoccupation with failure & 15.50 & 17.50 & 33.67 & 25.83 & 7.50 & Reluctance to Simplify & 23.83 & 32.83 & 28.00 & 12.83 & 2.50 \\
\hline Reluctance to Simplify & 6.67 & 24.79 & 30.21 & 22.71 & 15.63 & \begin{tabular}{|l|} 
Sensitivity to operations \\
\end{tabular} & 22.55 & 28.55 & 24.91 & 18.36 & 5.64 \\
\hline Sensitivity to operations & 5.00 & 15.68 & 32.50 & 27.05 & 19.77 & Commitment to resilience & 17.17 & 29.00 & 25.17 & 22.33 & 6.33 \\
\hline Commitment to resilience & 1.88 & 8.33 & 21.25 & 37.92 & 6.63 & Deference to expertise & 30.00 & 23.75 & 21.75 & 17.75 & 6.75 \\
\hline Deference to expertise & 35.00 & 25.31 & 17.81 & 15.63 & 6.25 & COMPANY G & & & & & \\
\hline \begin{tabular}{|l} 
COMPANYC \\
Preoccunation
\end{tabular} & 33 & & 38.44 & & 756 & Preoccupation with failure & 46.27 & 37.47 & 13.73 & 2.53 & 0.00 \\
\hline Reluctance to Simplify & 16.94 & 35.83 & 30.00 & 20.44 & 0.28 & Reluctance to Simplify & 26.83 & 41.00 & 28.50 & 3.67 & 0.00 \\
\hline Sensitivity to operations & 5.76 & 25.15 & 35.76 & 24.85 & 8.48 & Sensitivity to operations & 23.09 & 38.36 & 31.45 & 6.91 & 0.18 \\
\hline Commitment to resilience & 7.22 & 17.50 & 41.94 & 28.33 & 5.00 & Commitment to resilience & 25.83 & 34.67 & 26.00 & 13.33 & 0.17 \\
\hline Deference to expertise & 40.83 & 26.25 & 19.17 & 12.08 & 1.67 & Deference to expertise & 39.50 & 26.00 & 22.75 & 11.25 & 0.50 \\
\hline COMPANYD & & & & & & COMPANYH & & & & & \\
\hline Preoccupation with failure & 13.33 & 26.22 & 35.78 & 23.56 & 1.11 & Preoccupation with failure & 49.05 & 40.67 & 9.52 & 0.76 & 0.00 \\
\hline Reluctance to Simplify & 21.11 & 28.89 & 25.56 & 18.89 & 5.56 & Reluctance to Simplify & 24.76 & 43.93 & 27.98 & 3.33 & 0.00 \\
\hline Sensitivity to operations & 10.61 & 16.97 & 20.30 & 32.12 & 20.00 & Sensitivity to operations & 25.06 & 40.00 & 26.88 & 7.14 & 0.91 \\
\hline Commitment to resilience & 6.11 & 26.11 & 36.11 & 15.28 & 16.39 & Commitment to resilience & 39.88 & 37.14 & 16.67 & 5.83 & 0.48 \\
\hline Deference to expertise & 27.08 & 23.75 & 20.83 & 17.08 & 11.25 & Deference to expertise & 43.39 & 32.50 & 22.50 & 1.61 & 0.00 \\
\hline
\end{tabular}

Table 18: Detailed organisational maturity comparison

Considering preoccupation with failure, 'B', 'C', and ' $\mathrm{D}$ ' are on level 3. 'B', pulling towards level 4, is more mature than ' $C$ ' and ' $D$ ' that are pulling towards level 2. Applying the pull calculation to ' $C$ ' and ' $D$ ' will show that ' $\mathrm{C}$ ' with a pull of 0.65 towards level 2 is more matured with respect to preoccupation with failure than ' $\mathrm{D}$ ' with a pull of 0.73 towards level 2 . The same process could be applied to all the other HRO principles.

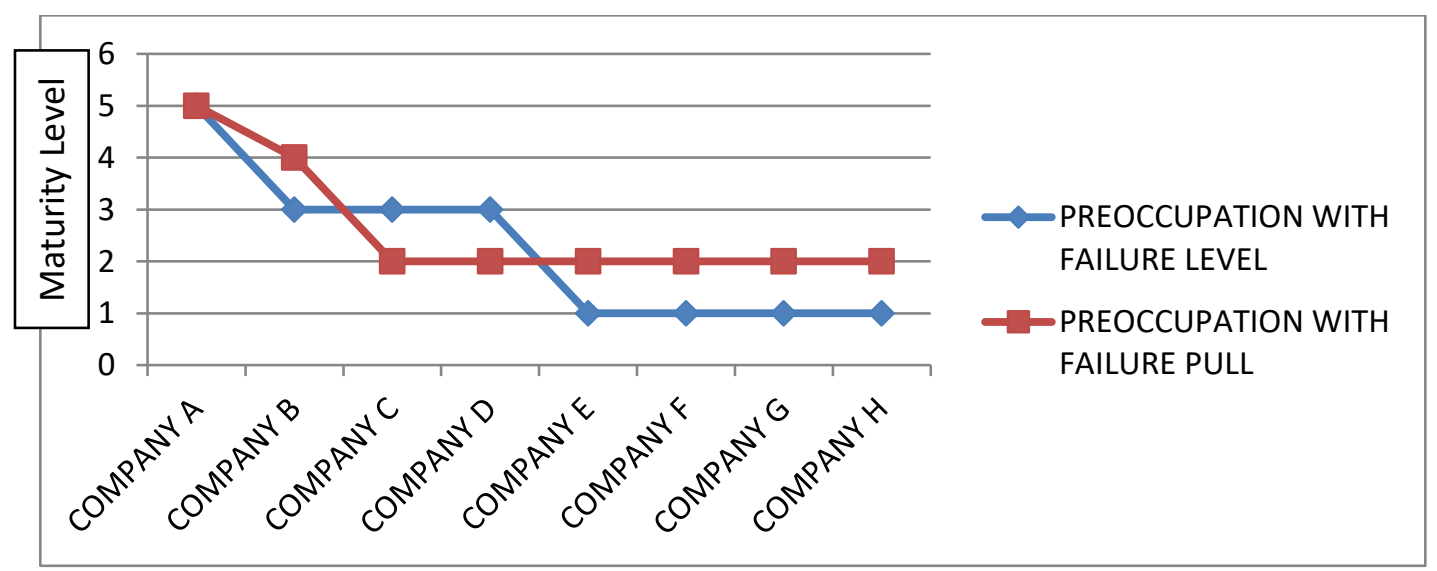

Figure 6 - A graph showing a comparison of the organisations in terms of their preoccupation with failure. 


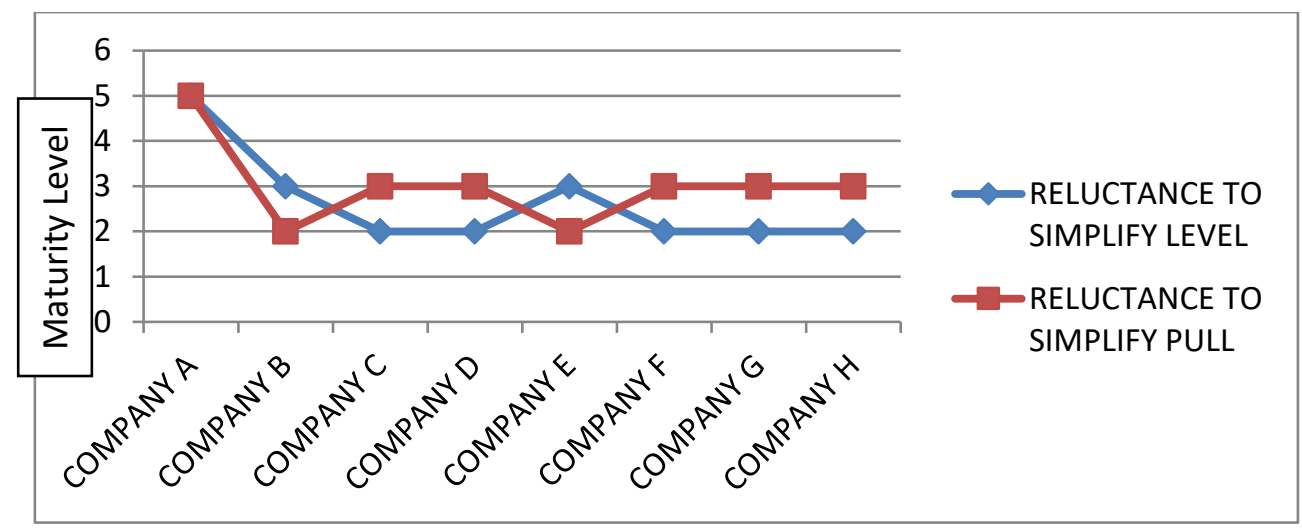

Figure 7 - A graph showing a comparison of the organisations in terms of their reluctance to simplify.

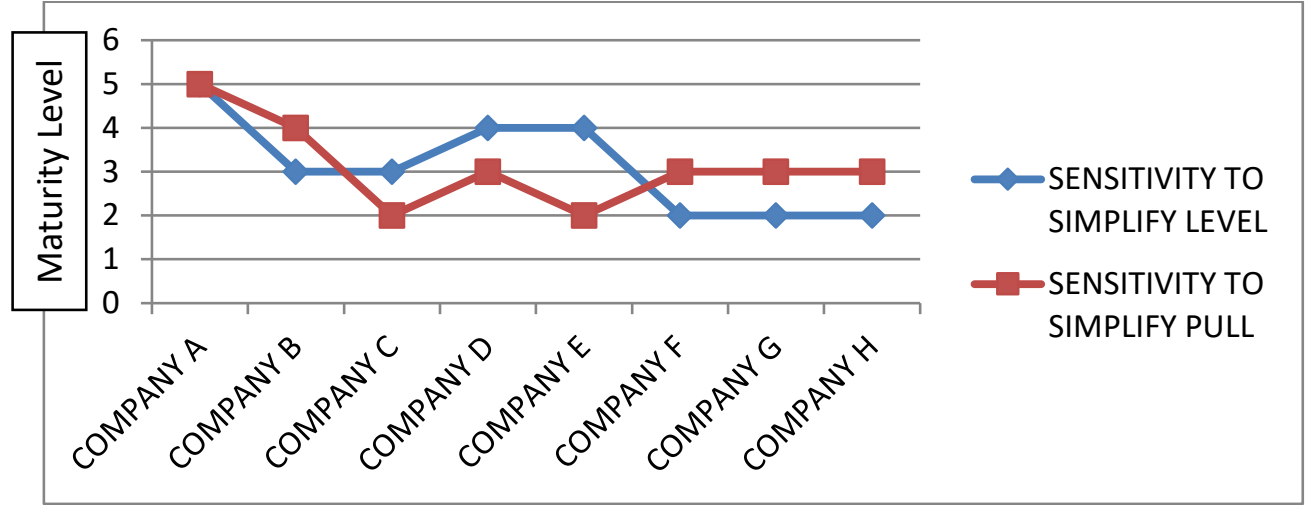

Figure 8 - A graph showing a comparison of the organisations in terms of their sensitivity to operations.

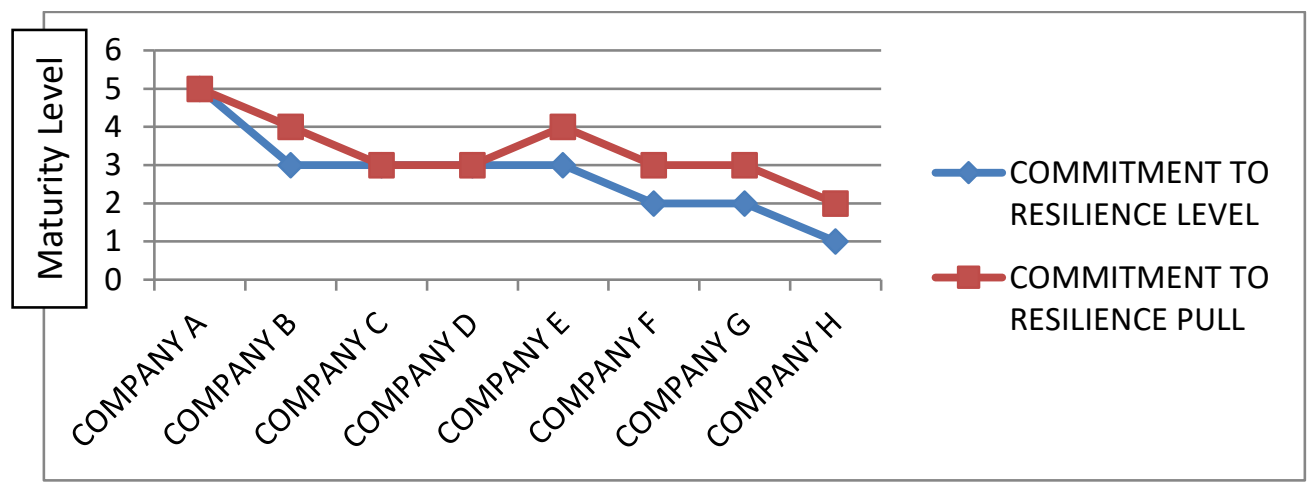

Figure 9 - A graph showing a comparison of the organisations in terms of their commitment to resilience.

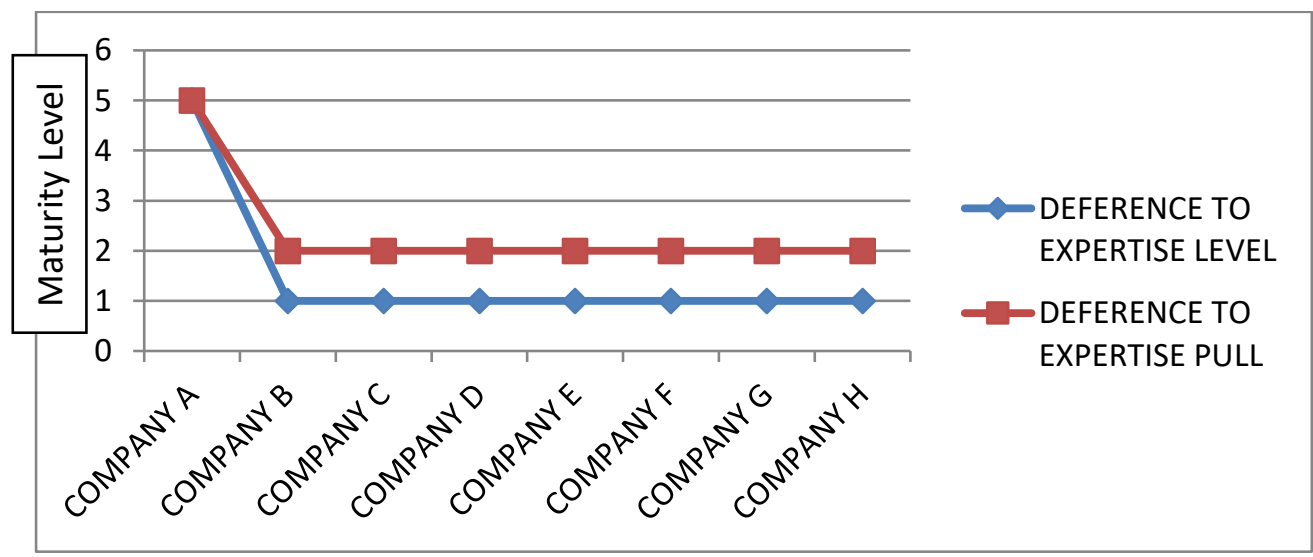

Figure 10 - A graph showing a comparison of the organisations in terms of their deference to expertise. 
Finally the framework could also benchmark against peers. A high level comparison of companies C and D (table 19) shows both organisations to be close on the average high level behaviours. They are both on the same maturity level 3 with pulls towards level 2 . There are also fairly pulled towards level 4 at 0.62 and 0.77 respectively.

Table 19: High level comparison of companies C and D

\begin{tabular}{|l|c|c|c|c|c|}
\hline \multicolumn{4}{|c|}{ COMPARING THE MATURITY OF THE ORGANIZATIONS } \\
\hline ORGANIZATIONS & SILENT & STARTER & STABLE & SUSTAIN & SUMMIT \\
\hline COMPANY C & 0.59 & 0.77 & ML & 0.62 & 0.14 \\
\hline COMPANY D & 0.56 & 0.88 & ML & 0.77 & 0.39 \\
\hline
\end{tabular}

A closer look at the detailed comparison (table 20) would highlight the key differences. In their sensitivity to operations, company $\mathrm{C}$ is at maturity level 3 with slightly more pull level 2, while Company D is more mature at level 4 with slightly higher pull towards level 3 is slightly. All the HRO principles for the peers could be compared in the same way.

Table 20: Detailed comparison of companies C and D

\begin{tabular}{|l|c|c|c|c|c|}
\hline \multicolumn{5}{|c|}{ COMPARING THE MATURITY OF THE ORGANIZATIONS } \\
\hline ORGANIZATIONS & SILENT & STARTER & STABLE & SUSTAIN & SUMMIT \\
\hline COMPANY C & & & & & \\
\hline Preoccupation with failure & 11.33 & 22.22 & 38.44 & 20.44 & 7.56 \\
\hline Reluctance to Simplify & 16.94 & 35.83 & 30.00 & 16.94 & 0.28 \\
\hline Sensitivity to operations & 5.76 & 25.15 & 35.76 & 24.85 & 8.48 \\
\hline Commitment to resilience & 7.22 & 17.50 & 41.94 & 28.33 & 5.00 \\
\hline Deference to expertise & 40.83 & 26.25 & 19.17 & 12.08 & 1.67 \\
\hline COMPANY D & & & & & \\
\hline Preoccupation with failure & 13.33 & 26.22 & 35.78 & 23.56 & 1.11 \\
\hline Reluctance to Simplify & 21.11 & 28.89 & 25.56 & 18.89 & 5.56 \\
\hline Sensitivity to operations & 10.61 & 16.97 & 20.30 & 32.12 & 20.00 \\
\hline Commitment to resilience & 6.11 & 26.11 & 36.11 & 15.28 & 16.39 \\
\hline Deference to expertise & 27.08 & 23.75 & 20.83 & 17.08 & 11.25 \\
\hline
\end{tabular}

\begin{tabular}{|c|l|}
\hline & \\
\hline LEGEND & \\
\hline & \\
\hline ML & CURRENT MATURITY LEVEL \\
\hline & HIGH PULL \\
\hline & \\
\hline & \\
\hline LEGEND & \\
\hline & \\
\hline ML & CURRENT MATURITY LEVEL \\
\hline & HIGH PULL \\
\hline & \\
\hline
\end{tabular}

\subsection{Organisational learning and Improvement using FORM}

The route organisations would choose to improve their organisational reliability would be determined by amount of resources they are willing to commit. For best results, a gradual and wholesome implementation is suggested. The improvement actions would normally be in a gradual and stepwise manner, in which case, the organisations would take incremental actions to improve their maturity one level at a time and grow the maturity over time. This approach is similar to the observations of O’Neil \& Krane (2012) where they concluded that HRO characteristics improve incrementally over a long period of time as long as the leadership commits to supporting the change and are able to motivate the whole organisation to support the initiative. This gradual and incremental approach could potentially pose some challenges in cases where the pull towards a higher maturity level is very high. A pull of 0.95 towards from level 3 towards level 4 (Company B in table 17) suggests that the organisation already exhibits a lot of level 4 behaviours. A smarter decision in this case would therefore be to 
begin to implement level 5 behaviours instead of committing resources on level 4 behaviours. Where the organisation is at maturity level 5 , it would be expected to sustain the maturity by continuously assessing its behaviours against the level 5 behaviours.

Vogus \& Sutcliffe (2007b), O’Neil \& Krane (2012) and Weick \& Sutcliffe (2015) cited leadership and policy makers, as well as the trust in these leaders as the engines that drives the organisational reliability improvement. They would make the policies and act build trust among organisation towards mindfulness. This trust eventually begins to drive the organisation towards maturity. Where an organisation is unable to the commit resources required to implement all $5 \mathrm{HRO}$ principles at the same time, it could chose to commit more resources to its weakest principle(s) as a means of boosting the average maturity level. This route must be used in conjunction with an organisational risk analysis. Labib et al (2009), in their work on total reliability and maintenance management awards observed that although all measures of quality are important, there are different weights assigned to different factors in the design of the elements of such an award. This paper assumes an equal weighting for all the $5 \mathrm{HRO}$ principles. An organisational risk analysis might recommend a different weighting for the principles due to the prevalent risk factors. Company B might for instance, consider preoccupation with failure to be its most vulnerable point and could choose to commit more resources to it. This does not preclude the organisation from striving for reliability in all five principles as one of the defining characteristics of collective mindfulness is the simultaneous presence of high levels of each of the five HRO principles. A future research will investigate the applicability of different weighting scales for the HRO principles.

The Organisational Reliability Maturity Model $\left(\mathrm{ORM}^{2}\right)$ is used in conjunction with the Framework for Organisational Reliability Maturity (FORM) to propose organisational improvement behaviours. Considering Company $G$ and $H$ (table 21), both organisations are at maturity level 2 with pulls towards level 1 
Table 21: Applying $\mathrm{ORM}^{2}$ to Company $\mathrm{G}$ and Company $\mathrm{H}$

\begin{tabular}{|c|c|c|c|c|c|c|c|}
\hline \multicolumn{7}{|c|}{ COMPANY H (RESTAURANT CHAIN) } & \multirow[b]{2}{*}{ Pull } \\
\hline Level & $\begin{array}{c}\text { Preoccupation with } \\
\text { Failure }\end{array}$ & $\begin{array}{l}\text { Reluctance to } \\
\text { Simplify }\end{array}$ & $\begin{array}{c}\text { Sensitivity to } \\
\text { Operations }\end{array}$ & $\begin{array}{l}\text { Commitment to } \\
\text { Resilience }\end{array}$ & $\begin{array}{l}\text { Deference to } \\
\text { Expertise }\end{array}$ & $\begin{array}{l}\text { Average } \\
\text { Score }\end{array}$ & \\
\hline 5 & 0.00 & 0.00 & 0.91 & 0.48 & 0.00 & 0.28 & 0.01 \\
\hline 4 & 0.76 & 3.33 & 7.14 & 5.83 & 1.61 & 3.74 & 0.10 \\
\hline 3 & 9.52 & 27.98 & 26.88 & 16.67 & 22.50 & 20.71 & 0.53 \\
\hline 2 & 40.67 & 43.93 & 40.00 & 37.14 & 32.50 & 38.85 & 0.00 \\
\hline $\mathbf{1}$ & 49.05 & 24.76 & 25.06 & 39.88 & 43.39 & 36.43 & 0.94 \\
\hline \multicolumn{7}{|c|}{ COMPANY G (RESTAURANT CHAIN) } & \\
\hline Level & $\begin{array}{c}\text { Preoccupation with } \\
\text { Failure }\end{array}$ & $\begin{array}{l}\text { Reluctance to } \\
\text { Simplify }\end{array}$ & $\begin{array}{c}\text { Sensitivity to } \\
\text { Operations }\end{array}$ & $\begin{array}{c}\text { Commitment to } \\
\text { Resilience }\end{array}$ & $\begin{array}{l}\text { Deference to } \\
\text { Expertise }\end{array}$ & $\begin{array}{c}\text { Average } \\
\text { Score }\end{array}$ & Pull \\
\hline 5 & 0.00 & 0.00 & 0.18 & 0.17 & 0.50 & 0.17 & 0.00 \\
\hline 4 & 2.53 & 3.67 & 6.91 & 13.33 & 11.25 & 7.54 & 0.21 \\
\hline 3 & 13.73 & 28.50 & 31.45 & 26.00 & 22.75 & 24.49 & 0.69 \\
\hline 2 & 37.47 & 41.00 & 38.36 & 34.67 & 26.00 & 35.50 & 0.00 \\
\hline 1 & 46.27 & 26.83 & 23.09 & 25.83 & 39.50 & 32.30 & 0.91 \\
\hline
\end{tabular}

From $\mathrm{ORM}^{2}$, and considering preoccupation with failure, both organisations do not report near misses or incidents, neither is there a process in place to manage incidents. They consider failure to be the result of someone's error and there are punishments for people found to cause a failure. The managements are considered as being difficult to approach. Both organisations pull strongly towards level 2 at 0.81 and 0.83 respectively, meaning that a large percentage may have already started to report some incidents or near misses, but there is no defined process to manage incidents, neither is there a formal communication channel with management. A smart recommendation would therefore be for the organisations to begin to implement level 3 behaviours. Such behaviour would include developing and implementing a formalised incident management process, communication process, and rewards process. A robust incident management process would include a feedback process to improve future process design, modify existing process or implement cultural change. Similarly, both organisations are also on maturity level 2 in their reluctance to simplify with high pulls of 0.70 and 0.64 respectively. Again, the smart recommendation would be to implement level 3 behaviours that aim at process standardisation.

While Company $H$ is at level 1 in commitment to resilience with a high pull of 0.93 towards level 2, Company $G$ is at level 2 with a high pull of 0.75 towards level 3. Company $H$ would therefore be smart enough to begin to encourage level 3 behaviours, while Company $G$ would encourage level 4 behaviours. All the behaviours would be defined in $\mathrm{ORM}^{2}$. Finally both organisations are at level 1 in their deference to expertise. While Company $H$ has a pull of 0.75 towards level 2, Company $G$ has a pull of 0.68 towards level 2. Company $H$ is additionally being pulled strongly 0.52 towards level 3 , while Company $G$ is additionally being pulled strongly at 0.58 towards level 3. The smart choice would therefore be to begin to encourage level 4 behaviours in both 
organisations. At level 4, the most senior would normally yield responsibility to the most experienced people during an emergency with emphasis is on yield, as the process is intentional and not out of coercion.

\subsection{Conclusions}

The paper explores important and often neglected aspects of HRO research - How can organisations become reliable? How do we measure the reliability of the organisation? Can this measurement be extended to diverse organisations? To what purpose would this be? Our development of $\mathrm{ORM}^{2}$ a staged maturity model for organisational reliability and FORM, the framework for organisational reliability maturity, as well as their deployment in eight diverse organisations in different industries leads us to conclude that it is possible to measure organisational reliability and develop a standardized framework for it. We also conclude that HRO principle could potentially be deployed by any organisation irrespective of location, size, or type of industry. We recommend a staged and gradual implementation for best results. We also conclude that organisations could use this measurement framework for self-assessment, to predict the potential to improve or retrogress, to benchmark, and for organisational learning and performance improvement towards higher reliability. We find that with an improved mindfulness, organisations would tend towards more error free operations and therefore towards improved safety. We also find that this framework has the key features of scalability, simplicity, and ease of use.

Future research extend the diversity and expand the study further into more industries and organisations with varying degrees of complexity, coupling, size, and age. This research used an equal weighting scale for all HRO behaviours. Another research would seek to investigate the applicability of different weighting scales for the HRO behaviours as done for quality dimension and see if this could potentially help organisations towards higher reliability. 
Alothman, A. (2016) A detailed view of high reliability organization models in the oil industry. Oil Gas Res 2:119. doi: $10.4172 / 2472-0518.1000119$

Antil, P. (1991) The maintenance organisational maturity grid, Maintenance Conference, March, COMAC Publications, Birmingham

Ashley, H. M., Farris, R. K., \& Richards, R. E. (2009) Achieving high reliability operations through multiprogram integration, Sixth American Nuclear Society International Topical Meeting on Nuclear Plant Instrumentation, Illinois: LaGrange Park

Ausserhofer, D., Schubert, M., Desmedt, M., Blegen, M. A., De Geest, S., \& Schwendimann, R. (2013) The association of patient safety climate and nurse-related organizational factors with selected patient outcomes: A cross-sectional survey. International journal of nursing studies, 50(2), 240-252

Aven, T. \& Krohn, B. S. (2014) A new perspective on how to understand, assess and manage risk and the unforeseen. Reliability Engineering and System Safety, 121, pp.1-10

Azzaro, J. A. (2005) Understanding a high performance university development organisation: leadership and best practices, $\mathrm{PhD}$ thesis

Backlund, F., Chronéer, D., \& Sundqvist, E. (2014) Project management maturity models-A critical review: A case study within Swedish engineering and construction organizations. Procedia-Social and Behavioural Sciences, 119, 837-846

Baker, D. P., Day, R., \& Salas, E. (2006) Teamwork as an essential component of high reliability organisations, Health Research and Educational Trust, 41 (4), 1576-1598

Barratt, N. (2010). Lost voices from the titanic: the definitive oral history, London: Random House. ISBN 9781-84809-151-1

Beadell, B. B, (2009) CMMI as contemporary iron cage: a grounded analysis from the perspective of practicing engineers in defence engineering. The school of education of the University of St. Thomas, St. Paul, Minnesota

Bellamy, G. T., Crawford, L., Marshall, L. H., \& Coulter, G. A. (2005) The fail-safe schools challenge: leadership possibilities from high reliability organisations. Educational Administration Quarterly; 41(3): 383412

Berardi, P. J. (2010) Measuring high reliability characteristics of the organisation, US: Kansas City Fire 
Department http://www.usfa.fema.gov/pdf/efop/efo44533.pdf, assessed 20th November 2016

Bergström, J., van Winsen, R., \& Henriqson, E. (2015) On the rationale of resilience in the domain of safety: A literature review. Reliability Engineering \& System Safety, 141, 131-141.

Bierly, P. E., \& Spender, J. C. (1995) Culture and high reliability organisations: The case of a nuclear submarine. Journal of Management, 21 (4), 639-656

Broadribb, M. P. (2015) What have we really learned? Twenty five years after Piper Alpha. Process Safety Progress, 34(1), 16-23

Busby, J. S. (2006) Failure to mobilize in reliability-seeking organisations: two cases from the UK railway. J Manage Stud; 43(6): 1375- 1393

Carr, A. (2016) Chipotle eats itself. Fast Company, https://www.fastcompany.com/3064068/chipotle-eats-itself assessed June 17, 2018

Carlo, J. L., Lyytinen, K., \& Boland Jr, R. J. (2012) Dialectics of Collective Minding: Contradictory Appropriations of Information Technology in a High-Risk Project. MIS Quarterly, 36(4), 1081-1108

Chassin, M. R., \& Loeb, J. M. (2011) The ongoing quality improvement journey: next stop, high reliability. Health Affairs, 30(4), 559-568

Chassin, M. R., \& Loeb, J. M. (2013) High-Reliability Health Care: Getting There from Here. Milbank Quarterly, 91(3), 459-490

Ciravegna, L., \& Brenes, E. R. (2016) Learning to become a high reliability organisation in the food retail business. Journal of Business Research, 69(10), 4499-4506

Costella, M. F., Saurin, T. A., \& Guimaraes, L. B. (2009) A method for assessing health and safety management systems from the resilience engineering perspective, Safety Science, 47, 1056-1067

Crosby, P. B. (1979) Quality is free: the art of making quality certain, New York, NY: McGraw-Hill Companies Fernandez, O., Labib, A.W., Walmesly, R., \& Petty, D. J. (2003) A decision support maintenance management system: development and implementation, International Journal of Quality \& Reliability Management, 20(8), pp. $965-979$

Frankel, A. S., Leonard, M. W., \& Denham, C. R. (2006) Fair and just culture, team behaviour, and leadership engagement: The tools to achieve high reliability. Health Services Research, 41 (4), 1690-1709 
Grabowski, M. \& Roberts, K. H. (2016) Reliability seeking virtual organizations: Challenges for high reliability organizations and resilience engineering. Safety Science

Gupta, A. (2010) Organization's size and span of control. Practical Management: Transforming Theories into Practices

Haavik, T. K., Antonsen, S., Rosness, R., \& Hale, A. (2016) HRO and RE: a pragmatic perspective, Safety Science

Hales, D. N. \& Chakravorty, S. S. (2016) Creating high reliability organisations using mindfulness. Journal of Business Research, 69(8), 2873-2881

Harvey, E. J., Waterson, P., \& Dainty, A. R. (2016) Applying HRO and resilience engineering to construction: Barriers and opportunities. Safety Science

Hofmann, D., Jacobs, R., \& Landy, F. (1995) High reliability process industries: Individual, micro and macro organisational influences on performance, Journal of Safety Research, 26 (3), 131-149

Hopkins, A. (2009) Failure to learn: The BP Texas City refinery disaster, Australia: CCH Australian Limited.

Huang, D. \& Zhang, W. (2010) CMMI in medium \& small enterprises: problems and solutions, in: Proceedings of the 2nd IEEE International Conference on Information Management and Engineering, 2010, pp. 171-174

INSAG-7 (1992) The Chernobyl Accident: Updating of insag-1, a report by the international nuclear safety advisory group, international atomic energy agency, Vienna, Austria

Introna, V., Cesarotti, V., Benedetti, M., Biagiotti, S., \& Rotunno, R. (2014) Energy Management Maturity Model: An organizational tool to foster the continuous reduction of energy consumption in companies. Journal of Cleaner Production, 83, 108-117

Janofsky, M. (1997) 25 million pounds of beef is recalled. A New York Times publication https://www.nytimes.com/1997/08/22/us/25-million-pounds-of-beef-is-recalled.html assessed June 12, 2018

Jeffcott, S., Pidgeon, N., Weyman, A., \& Walls, J. (2006) Risk, trust, and safety culture in UK train operating companies. Risk Anal; 26(5): 1105-1121

Keller, P. (2004) Managing the unexpected in prescribed fire and fire use operations: a workshop on the high reliability organisation. Fort Collins, CO: US Department of Agriculture, Forest Service, Rocky Mountain Research Station 
Kosieradzka, A. (2017). Maturity Model for Production Management. Procedia Engineering, 182, 342-349

La Porte, T., \& Consolini, P. (1998) Theoretical and operational challenges of 'high reliability organisations': air traffic control and aircraft carriers, International Journal of Public Administration, 21 (6-8), 847-852

Labib, A. (2014) Learning from failures: decision analysis of major disasters, Elsevier

Labib, A.W., Franlund, J., \& Vamvalis, C. (2009) Benchmarking Best Practice: Towards a Total Reliability \& Maintenance Management Award, Journal of Maintenance \& Asset Management, ISSN 0952-2110, Vol 4 No 25, pp 34-39

Labib, A. \& Harris, M. J. (2015) Learning how to learn from failures - the Fukushima nuclear disaster. Engineering Failure Analysis, 47, 117-128

Labib, A. \& Read, M. (2013) Not just rearranging the deckchairs on the Titanic: Learning from failures through Risk and Reliability Analysis. Safety science, 51(1), pp.397-413

Labib, A., \& Read, M. (2015) A hybrid model for learning from failures: the Hurricane Katrina disaster. Expert Systems with Applications, 42(21), 7869-7881

Langer, E. J. (2014). Mindfulness: 25th anniversary ed. A Merloyd Lawrence Book, Da Capo Lifelong Books

Le Coze, J. C. (2016) Vive la diversité! High Reliability Organisation (HRO) and Resilience Engineering (RE). Safety Science

Lekka, C. (2011) High reliability organisations, a review of the literature, Health and Safety Laboratory for Health and Safety Executives, RR 899

Lekka, C., and Sugden, C. (2011) Successes and challenges of implementing high reliability principles: a case study of a UK oil refinery, Process Safety and Environmental Protection.

Li, W., Zhang, L. and Liang, W. (2017) An Accident Causation Analysis and Taxonomy (ACAT) model of complex industrial system from both system safety and control theory perspectives, Safety science, 92, pp.94103

Madsen, P., Desai, V., Roberts, K., \& Wong, D. (2006) Mitigating hazards through continuing design: the birth and evolution of a paediatric intensive care unit, Organisation Science, 17 (2), 239-248

Miller, B. M., and Horsley, S. J. (2009) Digging deeper: crisis management in the coal industry, Journal of Applied Communication Research; 37(3): 298-316 
Moura, R., Beer, M., Patelli, E., Lewis, J., \& Knoll, F. (2016) Learning from major accidents to improve system design. Safety science, $84,37-45$

Nestle, Marion (2010) Safe Food: The Politics of Food Safety, 2nd Revised ed. Berkeley, CA: University of California Press

Nikkhou, S., Taghizadeh, K., \& Hajiyakhchali, S. (2016) Designing a Portfolio Management Maturity Model (Elena). Procedia-Social and Behavioral Sciences, 226, 318-325

O'Neil, P. D. (2011) High reliability systems and the provision of a critical transportation service, J Contingencies and Crisis Management; 19(3): 158-168

O'Neil, P. D., \& Krane, D. (2012). Policy and Organizational Change in the Federal Aviation Administration: The Ontogenesis of a High-Reliability Organization. Public Administration Review, 72(1), 98-111.

Oliveira, M. A., Lopes, I. and Figueiredo, D. L. (2012) Maintenance management based on organisation maturity level, International Conference on Industrial Engineering and Operations Management ICIEOM July 9 $-11$

Perrow, C. (1984) Normal accidents: Living with high-risk technologies. New York: Basic Books

Provera, B., Montefusco, A., \& Canato, A. (2010) A 'no blame'approach to organizational learning. British Journal of Management, 21(4), 1057-1074

Righi, A. W., Saurin, T. A., \& Wachs, P. (2015) A systematic literature review of resilience engineering: Research areas and a research agenda proposal. Reliability Engineering \& System Safety, 141, 142-152

Riley, W. (2009) High reliability and implications for nursing leaders, J Nurs Manag; 17(2): 238-246

Roberts, K. (1990) Some characteristics of one type of high reliability organisation. Organisation Science, 1 (2), $160-176$

Roberts, K., Stout, S., \& Halern, J. (1994) Decision dynamics in two high reliability military organisations, Management Science vol. 40(5), pp614-24

Roberts, K., Desai, V., \& Madsen, P. (2005) Reliability enhancement and demise at Back Bay Medical Centre Children's hospital, In P. Carayon (Ed.), Handbook of human factors and ergonomics in healthcare and patient safety (pp. 249-258). London: Erlbaum 
Rougier, J., Sparks, S., Aspinall, W., Cornell, S., Crosweller, S., Edwards, T., Freer, J., Hill, L., \& Hincks, T., (2010) SAPPUR: NERC scoping study on uncertainty and risk in natural hazards, BRISK, University of Bristol

Saka-Helmhout, A. (2007) Unravelling learning within multinational corporations, British Journal of Management, 18, pp. 294-310

Samuels, J. G. (2010) The application of high-reliability theory to promote pain management, J Nurs Adm; 40(11):471-6

Savioja, P., Norros, L., Salo, L., \& Aaltonen, I. (2014) Identifying resilience in proceduralised accident management activity of NPP operating crews. Safety Science, 68, pp.258-274

Schlosser, Eric (2001) Fast Food Nation. London: Penguin Books

Schulman, P. (2008) Assessing NASA's safety culture: the limits and possibilities of high-reliability theory, Arjen Boin 2008; 68(6): 1050-1062

Stralen, van, D., Calderon, R., Clements, P., Daniel, A., Rao, R., Padgett, J., Kausen, B., and Roberts, K. (2006) High reliability organisation methods facilitate initiation of mechanical ventilation in a paediatric nursing home, Society of Critical Care Medicine, $35^{\text {th }}$ Critical Care Congress, San Francisco, California, January 7-11

Stringfield, S. (1995) Attempting to enhance students' learning through innovative programs: the case for schools evolving into high reliability organisations. School Effectiveness and School Improvement 1995; $6(1): 67-96$

Stringfield, S., Reynolds, D., and Schaffer, E.C. (2008) Improving secondary students' academic achievement through a focus on reform reliability: 4- and 9-year findings from the high reliability schools project, School Effectiveness and School Improvement; 19(4):409-428

Sullivan, J. L., Rivard, P. E., Shin, M. H., \& Rosen, A. K. (2016) Applying the High Reliability Health Care Maturity model to assess hospital performance: A VA case study. Joint Commission journal on quality and patient safety, 42(9), 389-399

Sutcliffe, K. M. (2011) High reliability organisations (HROs), Best Practice \& Research Clinical Anaesthesiology, Volume 25, Issue 2, June, Pages 133-144, ISSN 1521-6896

Sutcliffe, K. M., Vogus, T. J., \& Dane, E. (2016). Mindfulness in organisations: A cross-level review. Annual Review of Organisational Psychology and Organisational Behavior, 3, 55-81

Taleb, N. N. (2010). The black swan: The impact of the highly improbable. Penguin Books. 
Tamuz, M., and Harrison, M. I. (2006) Improving safety in hospitals: Contributions of high reliability theory and normal accident theory, Health Research and Educational Trust, 41 (4), 1654-1673

Taylor, D. L., \& Angelle, P. S. (2000) High reliability organisations and transformational leadership as lenses for examining a school improvement effort, Southwest Educational Research Association, Texas

Tsoukas, H. and N. Mylonopoulos (2004) Introduction: Knowledge construction and creation in organizations, British Journal of Management, 15, pp. 1-8

Turner, B.A. (1978) Man-Made Disasters. London:Wykeham

Uskarc1, A., \& Demirörs, O. (2017) Do staged maturity models result in organisation-wide continuous process improvement? Insight from employees. Computer Standards \& Interfaces, 52, 25-40

Un, C. \& A. Cuervo-Cazurra (2004) Strategies for knowledge creation in firms, British Journal of Management, 15 , pp. $27-41$

Valorinta, M. (2009). Information technology and mindfulness in organizations. Industrial and Corporate Change, 18(5), 963-997

Vaughan, D. (1997) The Challenger launch decision: Risky technology, culture, and deviance at NASA. University of Chicago Press

Vogus, T. J., and Welbourne, T. M. (2003) Structuring for high-reliability: HR practices and mindful processes in reliability-seeking organisations, Journal of Organisational Behaviour, 24, 877-903

Vogus, T. J., \& Sutcliffe, K. M. (2007a) The safety organizing scale: Development and validation of a behavioral measure of safety culture in hospital nursing units. Medical Care, 45(1), 46-54

Vogus, T. J., \& Sutcliffe, K. M. (2007b) The impact of safety organizing, trusted leadership, and care pathways on reported medication errors in hospital nursing units. Medical Care, 45(10), 997-1002

Vogus, T. J., Cooil, B., Sitterding, M., \& Everett, L. Q. (2014). Safety organizing, emotional exhaustion, and turnover in hospital nursing units. Medical Care, 52(10), 870-876

Vogus, T. J., \& Iacobucci, D. (2016). Creating highly reliable health care: Reliability-enhancing work practices affect patient safety in hospitals. Industrial and Labor Relations Review, 69(4), 911-938

Waring, A. (2015) Managerial and non-technical factors in the development of human-created disasters: A review and research agenda. Safety science, 79, pp.254-267 
Weick, K. E. (2002). Puzzles in organizational learning: An exercise in disciplined imagination. British journal of management, 13(S2)

Weick, K. E., and Roberts, K. H. (1993) Collective mind in organisations: Heedful interrelating on flight decks, Administrative Science Quarterly, 38 (3), 357-381

Weick, K. \& K Sutcliffe (2001) Managing the Unexpected: Assuring High Performance in an Age of Complexity, San Francisco: Jossey-Bass

Weick, K. E., \& Sutcliffe, K. M. (2007) Managing the unexpected: Resilient performance in an age of uncertainty, $2^{\text {nd }}$ edn, San Francisco: Jossey-Bass

Weick, K. E. \& Sutcliffe, K. M. (2015) Managing the unexpected: sustained performance in a complex world, John Wiley \& Sons

Weick, K.E., Sutcliffe, K.M., \& Obstfeld, D. (2008). Crisis management: Parts 2 and 3. 3, 31-36, Sage: Thousand Oaks, CA.

Zietsma, C., M. Winn, O. Branzei and I. Vertinsky (2002) The war of the woods: facilitators and impediments of organizational learning processes, British Journal of Management, 13, pp. 61-74 